\title{
Hydrodynamic Bearing Structural Design of Blood Pump Based on Axial Passive Suspension Stability Analysis of Magnetic-Hydrodynamic Hybrid Suspension System
}

\author{
Peng Shen, Yiwen Wang *, Yun Chen, Pengqiang Fu, Lijie Zhou and Lijia Liu \\ Key Laboratory of Advanced Manufacturing and Intelligent Technology, Harbin University of Science and \\ Technology, Harbin 150080, China; 1710100002@STU.HRBUST.EDU.CN (P.S.); \\ 1920110087@STU.HRBUST.EDU.CN (Y.C.); pqfu@hrbust.edu.cn (P.F.); zhoulijie@hrbust.edu.cn (L.Z.); \\ liulijia@hrbust.edu.cn (L.L.) \\ * Correspondence: wyw@hrbust.edu.cn; Tel.: +86-0451-8639-0518
}

check for

updates

Citation: Shen, P.; Wang, Y.; Chen, Y.; Fu, P.; Zhou, L.; Liu, L.

Hydrodynamic Bearing Structural Design of Blood Pump Based on Axial Passive Suspension Stability Analysis of Magnetic-Hydrodynamic Hybrid Suspension System. Machines 2021, 9 , 255. https://doi.org/10.3390/ machines 9110255

Academic Editors: Mingcong Deng, Hongnian Yu and Changan Jiang

Received: 27 September 2021

Accepted: 25 October 2021

Published: 27 October 2021

Publisher's Note: MDPI stays neutral with regard to jurisdictional claims in published maps and institutional affiliations.

Copyright: (c) 2021 by the authors. Licensee MDPI, Basel, Switzerland. This article is an open access article distributed under the terms and conditions of the Creative Commons Attribution (CC BY) license (https:/ / creativecommons.org/licenses/by/ $4.0 /)$.

\begin{abstract}
Rotor suspension stability is one of the important performance indexes of a blood pump and the basis of determining whether the blood pump can be used in a clinic. Compared with the traditional magnetic suspension system, a single-winding, bearingless motor has the advantages of a compact structure, simple control system and low power consumption. In this pursuit, the present study aimed to envisage and design the magnetic suspension system coupled with a single-winding bearingless motor and permanent magnet bearings, establish the theoretical models of axial force and electromagnetic torque, and calculate the stiffness of the magnetic suspension system at the equilibrium point. Addressing the problem of the negative axial stiffness of the magnetic suspension system being negative, which leads to the instability of the suspension rotor, the hydrodynamic bearing structure was proposed and designed, and the critical stiffness to realize the stable suspension of the rotor was obtained based on the stability criterion of the rotor dynamics model. The optimal structural parameters of the hydrodynamic bearing are selected by integrating various factors based on the solution of the Reynolds equation and a stiffness analysis. Furthermore, the vibration experiment results proved that the blood pump rotor exhibited a good suspension stability, and the maximum offset under the impact external fluid was no more than $2 \mu \mathrm{m}$.
\end{abstract}

Keywords: blood pump; magnetic-hydrodynamic hybrid suspension system; passive suspension stability; stiffness; hydrodynamic bearing

\section{Introduction}

Heart failure is a common cardiovascular disease and implanting a blood pump is one of the effective ways to treat this kind of disease [1,2]. The earlier developed blood pumps exhibited a pulsatile flow blood pump that simulated cardiac contractions and relaxations, but faced problems such as a large volume, high noise, high failure rate, inability of implantation and a risk of bleeding and thrombosis, which seriously affected the clinical treatment effect [3]. Later, researchers developed the continuous-flow rotary blood pump, which greatly reduced its volume and weight and could be implanted into the abdominal cavity of the patients with heart failure. The typical products, such as the HeartMate II blood pump, are certified by the FDA and widely used in the clinical setting [4], but the mechanical bearing of the blood pump wears off and heats up after long-term use, making it easier to cause hemolysis, thrombosis, and other complications [5]. The rotor of the third-generation blood pump adopts a suspension support system that cancels the mechanical bearing structure, eliminates the blood damage caused by mechanical bearing, and has good blood compatibility [6,7]. As one of the remarkable characteristics of the third-generation blood pump, the suspension system of the rotor directly determines the operation stability and blood compatibility of the blood pump in practical applications. 
The suspension system of the blood pump includes the magnetic suspension, hydraulic suspension and magnetic hydrodynamic hybrid suspension. For the magnetichydrodynamic hybrid suspension blood pump, the combination of the magnetic bearing and hydraulic bearing is generally used to regulate the movement of the rotor, and the rotating motion is driven by a separate motor. Therefore, in order to realize the active control of the suspension and rotation, more windings, inverters and sensor components are required [8]. For the implantable blood pump, the increased volume of the blood pump increases to a certain extent, the weight and power consumption can adversely affect the implantation of the blood pump and the quality of life of the patients with heart failure. Therefore, reducing the number of power devices is one of the effective ways to reduce power consumption and volume.

Compared with the traditional drive mode of combining magnetic bearings and motor, the axial flux bearingless motor can produce a suspension force and rotating torque at the same time with only one three-phase winding, which greatly simplifies the structure and the control system. In addition, the axial flux motor has the characteristics of a small volume, light weight and high efficiency, when compared to the with radial flux motor. Thus, it has greater advantages in the miniaturization and reduced weight of the blood pump. For example, Toru [9] designed a suspension system with a double offset hybrid magnetic bearing. The upward magnetic pull generated by the magnetic bearing balanced the downward bias magnetic pull of the bearingless motor, and the impeller could be suspended in the axial direction center position of the blood pump through active regulation. The axial and tilt motion of the impeller were actively regulated by the electromagnetic bearing, while the radial motion was constrained by the passive stability. Nevertheless, the magnetic suspension system of the blood pump has problems, such as a large volume and complex structure. If the permanent magnet bearings are used to replace the electromagnetic bearing structure, and the only driving component is the bearingless motor, the number of driving components and the blood pump volume can be greatly reduced. In addition, the permanent magnets of the bearingless motor can adopt the magnetization mode of the Halbach array, which can improve the sinusoidality of the air gap flux and enhance the magnetic density. This kind of motor with a special magnetization direction helps to improve the motor efficiency and reduce the torque ripple on the basis of increasing the average torque [10-12]. However, the negative stiffness of the magnetic suspension system makes the impeller unable to suspend stably. The repulsive hydrodynamic bearing can eliminate the negative stiffness of the bearingless motor without adding hardware, ensure the rotor suspension stability, and helps to reduce the vibration of the rotor via damping.

Hydraulic bearings can be categorized into hydrostatic bearings and hydrodynamic bearings. The hydraulic suspension structure design and suspension stability analysis has been extensive studied [13,14]. For example, Wang et al. [15] designed a hydraulic bearing for the radial suspension support of an axial flow blood pump; established a theoretical model for the hydraulic bearing force; studied the influence law of the rotating speed and radial eccentricity on the bearing force through numerical simulation, and measured the magnetic-hydrodynamic, double-levitated impeller stability under different external circulation experiments via the Hall sensor and laser vibration meter. Similarly, Chung et al. [16] studied the rotor dynamic characteristics of the hydrodynamic bearing of the rotary blood pump at different flow rates and impeller speeds; obtained the stiffness coefficient and damping coefficient of the system by applying an external interference, and analyzed the influence of the law of speed and flowrate on the stiffness coefficient and damping coefficient. In order to improve the suspension stability of the blood pump and the hemolysis performance, Kosaka et al. optimized the number of spiral grooves, groove depth and bearing clearance of the hydrodynamic bearing structure and obtained the best parameter combination $[17,18]$. Kataoka et al. studied the rotor radial movement of the blood pump coupled with a hydrodynamic bearing and permanent magnetic bearing [19]. From the experimental results, it was found that the radial direction motion of the rotor 
had an unstable circular mode. The occurrence of the unstable rotation mode could be avoided by increasing the speed and adopting a symmetrical structure.

In conclusion, the hybrid suspension system of the axial flux, single-winding, bearingless motor, permanent magnet bearing, and hydrodynamic bearing solves the problems of a complex structure, heavy weight and high energy consumption. The structural design of the hydrodynamic bearing is closely related to the stiffness characteristics of the magnetic suspension system composed of a bearingless motor and permanent magnet bearing. However, there are few studies on the structural design and stability analysis of the hydrodynamic bearing based on the stiffness characteristics of a bearingless motor. Therefore, the present study was envisaged to decipher the axial force and stiffness characteristics of the suspension system by using a combination of theoretical calculations and simulation solutions. This study also aimed to design the hydrodynamic bearing structure according to the relationship between the stiffness and structural parameters and verify the suspension stability of the blood pump through experimental validation. Our study can lay the foundation for the active regulation of the rotor pose of the blood pump and the optimization of blood compatibility.

\section{Magnetic Suspension System Modeling}

\subsection{Structure and Working Principle}

The structure composition of the magnetic-hydrodynamic hybrid suspension centrifugal blood pump designed in this study is shown in Figure 1a. The blood pump shell was composed of the inlet, upper casing, lower casing, and motor casing, as shown in Figure 1b. The blood pump impeller structure was in the form of a closed straight blade cover plate. The upper end face was embedded with a concentric, movable, permanent magnetic ring, which was matched with the concentric, fixed magnetic ring of the upper casing to form a permanent magnetic bearing. The permanent magnets with different polarities were embedded in the lower end face of the impeller to cooperate with the motor stator, in order to realize the rotating motion of the impeller. Therefore, the impeller can also be regarded as the motor rotor. The impeller adopted the support scheme of the combination of passive and active suspension, and the rotating motion of the impeller was consistent with the driving mode of the ordinary, permanent, magnet-synchronous motor. The stator coil and iron core of the motor were placed in the motor casing to form a single-winding bearingless motor with the permanent magnets on the impeller. The hydrodynamic bearing was located on the upper and lower pump casing and exerted an axial fluid force on the impeller under the fluid action. Therefore, the impeller can be suspended in the blood pump cavity under the coupling action of the permanent magnet bearing, the motor electromagnetic force and the hydrodynamic bearing force.

As shown in Figure 2a, the structural design scheme of a single-winding bearingless motor consisted of a rotor backplate, magnetic pole, coils, iron core and stator yoke. The motor of the blood pump was an axial flux, bearingless, permanent, magnet-synchronous motor, which realized the rotation of the impeller in the form of single-winding structure, and cooperated with the permanent magnet bearing to ensure the stable suspension of the impeller in the pump casing. The structure composition and size of the bearingless motor stator are shown in Figure $2 b$. The Halbach array structure was adopted for a magnetic pole arrangement to improve the blood pump efficiency and reduce motor power consumption. Its structure is shown in Figure 2c. 


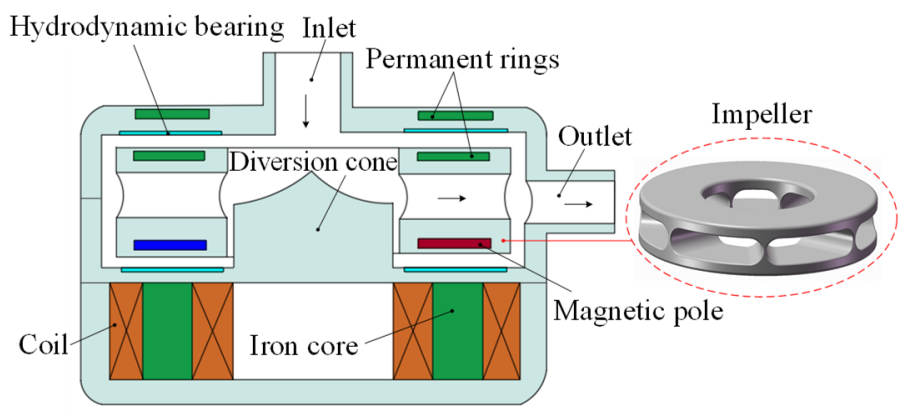

(a)

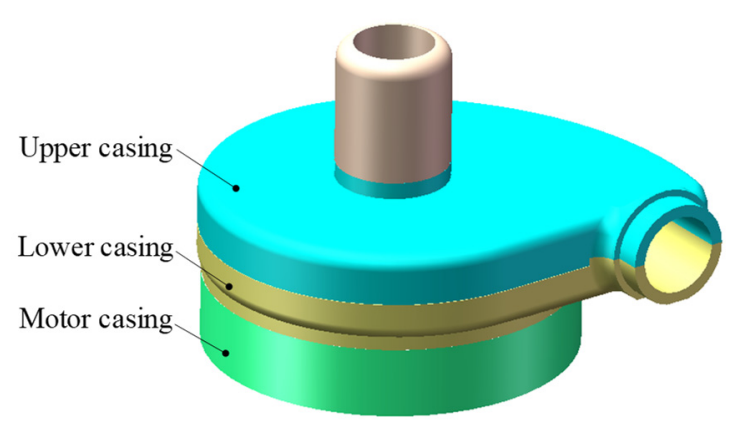

(b)

Figure 1. Magnetic-hydrodynamic hybrid suspension blood pump: (a) Structural composition of the blood pump; (b) Threedimensional casing model.

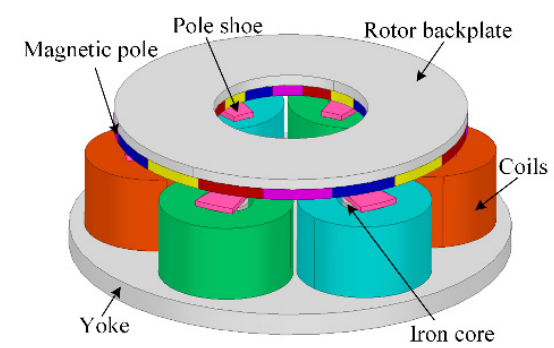

(a)

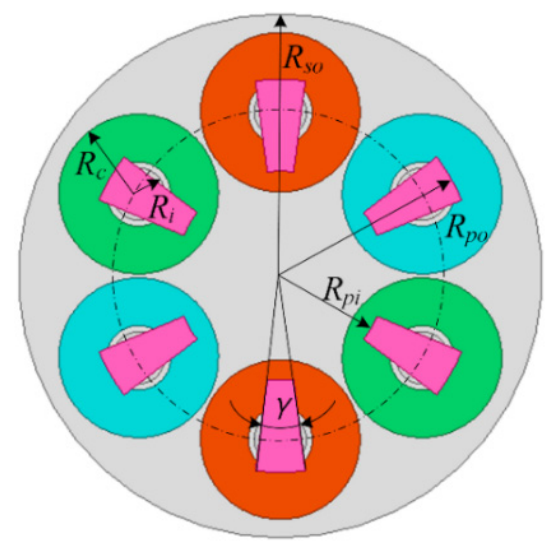

(b)

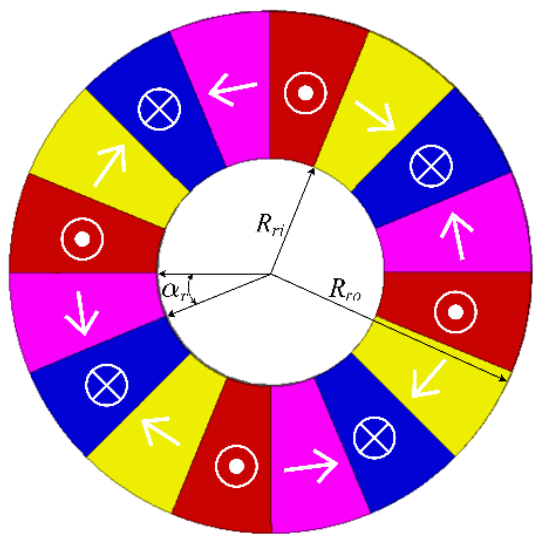

(c)

Figure 2. Bearingless motor of the blood pump: (a) Single-winding bearingless motor; (b) Motor stator; (c) Rotor with Halbach array.

\subsection{Modeling of the Bearingless Motor}

The magnetic poles of the motor rotor were fixed on the rotor backplate. Therefore, the motor was a non-salient pole structure, and the magnetic poles were magnetized according to the Halbach array arrangement. The specific composition of the magnetic suspension system and permanent magnet bearing are shown in Figure 3a,b.

The two concentric, permanent magnet rings embedded in the upper-end face of the impeller and the two concentric, permanent magnet rings embedded in the upper casing cooperated with each other, and the permanent magnet bearing generated a magnetic pull force in the $z$ axial direction. Therefore, the component of the magnetic force generated by the motor stator and the permanent magnet rings in the $z$ axial direction jointly determined the axial position of the impeller. The $x, y$ axial translation and $\phi_{x}, \phi_{y}$ rotation of the impeller were passively constrained by the magnetic coupling between the permanent magnet bearing and the bearingless motor. Therefore, the translation and rotation of the impeller in $x$ and $y$ axis direction were limited. Let the upper and lower air gaps of the rotor be represented as $g_{1}$ and $g_{0}$, respectively. When the rotor is translated $z$ in the positive axial direction due to disturbance, the upper and lower air gaps becomes $g_{1}-z$ and $g_{0}+z$. Therefore, in order to maintain the stable suspension and rotation of the impeller at the balance position, it is crucial to regulate the motor stator current. The specifications of the bearingless motor and permanent magnet bearing are shown in Table 1. 


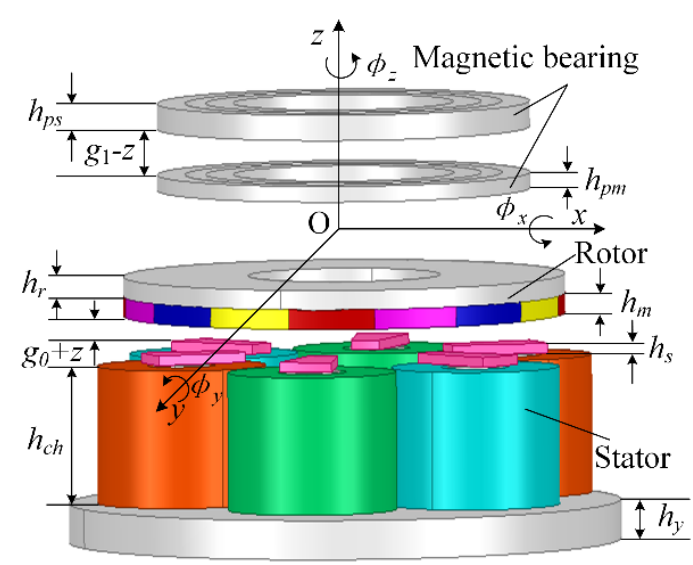

(a)

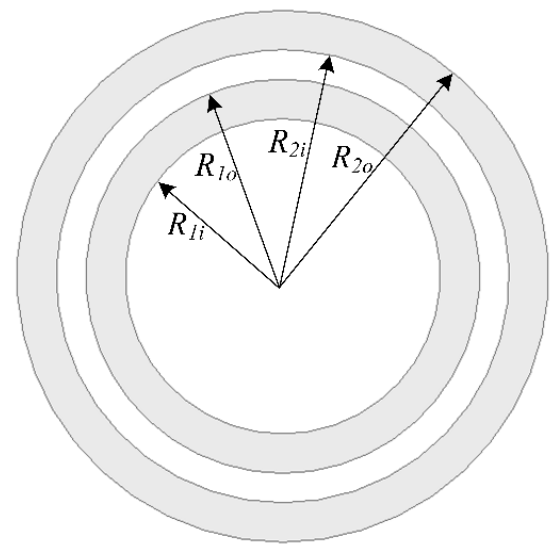

(b)

Figure 3. Hybrid magnetic suspension system with a single-winding bearingless motor and a permanent magnet bearing: (a) Hybrid magnetic suspension system; (b) permanent magnet bearing.

Table 1. Specifications of the magnetic suspension system.

\begin{tabular}{ccc}
\hline Symbol & Explanations & Size \\
\hline$R_{s o}$ & Outer radius of stator & $20(\mathrm{~mm})$ \\
$R_{p o}$ & Outer radius of pole shoe & $15(\mathrm{~mm})$ \\
$R_{p i}$ & Inner radius of pole shoe & $8(\mathrm{~mm})$ \\
$R_{c}$ & Coil radius & $6(\mathrm{~mm})$ \\
$R_{i}$ & Iron core radius & $2(\mathrm{~mm})$ \\
$\gamma$ & Angle of pole shoe & $15\left({ }^{\circ}\right)$ \\
$R_{r i}$ & Inner radius of rotor & $7(\mathrm{~mm})$ \\
$R_{r o}$ & Outer radius of rotor & $16(\mathrm{~mm})$ \\
$\alpha_{r}$ & Angle of magnet pole & $22.5\left(^{\circ}\right)$ \\
$h_{p s}$ & Thickness of static magnetic ring & $1.3(\mathrm{~mm})$ \\
$h_{p m}$ & Thickness of movable magnetic ring & $0.8(\mathrm{~mm})$ \\
$h_{r}$ & Rotor backplate thickness & $1(\mathrm{~mm})$ \\
$h_{c h}$ & Core height & $7(\mathrm{~mm})$ \\
$h_{m}$ & Magnetic pole thickness & $1(\mathrm{~mm})$ \\
$h_{s}$ & Thickness of pole shoe & $0.5(\mathrm{~mm})$ \\
$h_{y}$ & Yoke thickness & $2(\mathrm{~mm})$ \\
$R_{1 i}$ & Inner radius of magnetic bearing & $8(\mathrm{~mm})$ \\
$R_{1 o}$ & Outer radius of magnetic bearing & $10(\mathrm{~mm})$ \\
$R_{2 i}$ & Inner radius of magnetic bearing & $11.5(\mathrm{~mm})$ \\
$R_{2 o}$ & Outer radius of magnetic bearing & $13.5(\mathrm{~mm})$ \\
\hline
\end{tabular}

The bearingless motor stator adopted the structure of the three-phase concentrated windings. The three-phase windings, $A, B$ and $C$, were arranged in a space at an interval of $120^{\circ}$, and the number of turns was $N_{s}$. The rotor and stator structure of the bearingless motor, as shown in Figure $4 \mathrm{a}$, is used to analyze the rotation motion of the motor, expand the spatial structure of the motor along the circumferential direction and establish the coordinate system, as shown in Figure $4 \mathrm{~b}$. The direct axis and the quadrature axis are synchronous, dynamic coordinate systems fixed on the motor rotor, which are used to describe the rotating motion of the motor. The magnetic field direction of the motor is the $d$ axis and the axis perpendicular to the magnetic field direction is the $q$ axis. Therefore, the spatial phase difference between the $d$ axis and the $q$ axis is $\pi / 2$. Permanent magnets with different magnetic pole directions are pasted on the lower surface of the rotor of the bearingless motor, and the number $p$ of rotor pole pairs was four. The three-phase coils of the stator were fed with a sinusoidal current to drive the motor. The magnetic flux distribution $\psi$ formed by the magnetic field interaction of the permanent magnet and the 
motor energizing coil is shown by the black dotted arrow in Figure $4 \mathrm{~b}$. In order to study the rotor dynamic characteristics of blood pump, the magnetic field of the bearingless motor was theoretically analyzed using the inductance matrix method. The air gap magnetic energy was calculated by the magnetic flux distribution and inductance matrix, and the torque and axial electromagnetic force were obtained by deriving the rotation direction $\theta$ and $z$-axis direction. In order to calculate the inductance and deduce the electromagnetic force and torque model through the effective permeability, the magnetic field generated by the permanent magnet on the rotor was equivalent to a direct current excitation winding with the turns $N_{f}$ and current $i_{f}$.
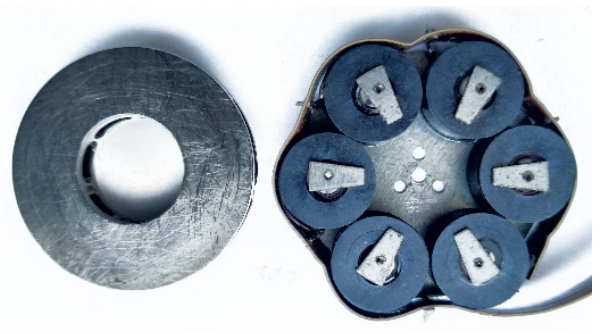

(a)

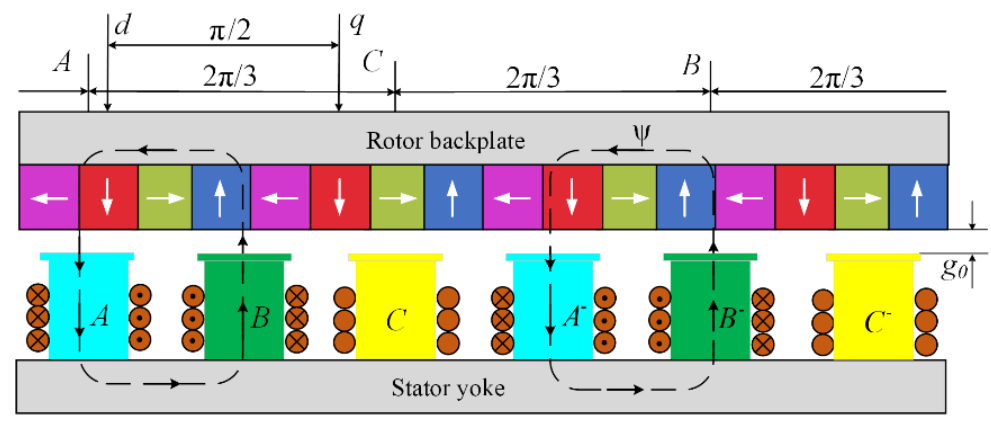

(b)

Figure 4. Bearingless motor structure and working principle diagram of the blood pump: (a) Rotor and stator of the bearingless motor; (b) Schematic representation of the working principle diagram.

The electromagnetic force and the torque of the bearingless motor were theoretically modeled, and the assumptions were as follows:

(a) The spatial distribution of the magnetomotive force was sinusoidal.

(b) The stator surface was smooth and the slot harmonics could be ignored.

(c) Magnetic saturation was ignored.

(d) The permeability of the stator core was infinite, and the permeability of the permanent magnet and air was considered equal to that of vacuum.

(e) The iron loss was ignored.

For the non-salient rotor, the self-inductance of the stator coil was independent of the rotor position angle $\theta$. Therefore, the self-inductance of the stator coil was constant, and the $d$ axis inductance and $q$ axis inductance were equal. The self-inductances of the three-phase stator coils are given by Equation (1):

$$
L_{a a}=L_{b b}=L_{c c}=\frac{N_{s} \psi}{i_{a}}+L_{a l}=L_{a a 0}+L_{a l}
$$

Therefore, the self-inductance of the stator was composed of $L_{a a 0}$ and $L_{a l}$, where $L_{a a 0}$ is the self-inductance component generated in the coil by the fundamental flux in the air gap; and $L_{a l}$ is the additional component generated for the leakage flux of armature winding, which is also called the leakage inductance $L_{a l}$. The self-inductance of a winding is generally a function of the air gap $g$ [20]. Therefore, the self-inductance of stator winding can be approximately expressed by Equation (2) with air gap $g$ :

$$
L_{a a 0}=\frac{L_{a a 0}^{\prime}}{g}
$$

where $L_{a a 0}^{\prime}$ is the stator magnetizing inductance multiplied by the air gap length, and the unit is Hm. $L_{a a 0}^{\prime}$ and $L_{a l}$ are constants, which are obtained by the motor parameter identification and the phase inductance measurement. The mutual-inductance between the two windings is the product of the self-inductance and $\cos \alpha$, whose phase angle difference 
is the electrical angle $\alpha$. Since the angle between the different phases of armature winding was $120^{\circ}$, the mutual inductances between the different phases of armature winding are equal, which is expressed by Equation (3):

$$
L_{a b}=L_{b a}=L_{a c}=-\frac{1}{2} L_{a a 0}=-\frac{1}{2} \frac{L_{a a 0}^{\prime}}{g}
$$

Similar to the self-inductance of stator, the self-inductance $L_{f}$ of the rotor excitation winding is expressed in Equation (4):

$$
L_{f f}=L_{f}=L_{f f 0}+L_{f l}=\frac{L_{f}^{\prime}}{g}+L_{f l}
$$

where $L_{f f 0}$ is the inductance generated by the fundamental component of magnetic flux in the air gap. The leakage inductance $L_{f l}$ of the rotor excitation winding is used to characterize the influence of permanent magnet leakage flux. The mutual inductance between the stator and rotor is related to the rotor position and changes periodically with $\theta$, so the mutual inductance between the excitation winding $f$ and phase winding $a$ is given by Eqaution (5):

$$
L_{a f}=L_{f a}=L_{m} \cos \theta=\frac{L_{m}^{\prime}}{g} \cos \theta
$$

where $L_{m}^{\prime}$ is the constant part of the mutual inductance of the motor stator and rotor. It was observed that the relationship between the self-inductance and the mutual inductance of the stator and rotor that the relationship $L_{m}^{\prime}=\sqrt{L_{a a 0}^{\prime} L_{f}^{\prime}}$ was satisfied. When the windings of the motor stator were three-phase symmetrical, $i_{a}+i_{b}+i_{c}=0$, and thus $i_{b}+i_{c}=-i_{a}$. On substituting the self-inductance of the above phase $A$ and the mutual inductance of the excitation winding $f$, the phases $B$ and $C$ into the flux linkage expression were obtained as shown in Equation (6):

$$
\lambda_{a}=\left(\frac{3}{2} L_{a a 0}+L_{a l}\right) i_{a}+L_{a f} i_{f}
$$

If the synchronous inductance $L_{s}=3 / 2 L_{a a 0}+L_{a l}$ is defined, the corresponding flux linkage equation of phase $A$ is:

$$
\lambda_{a}=L_{s} i_{a}+L_{a f} i_{f}
$$

Therefore, the phase voltage of the motor is composed of the voltage on the phase resistance and the back electromotive force, and its expression is:

$$
\left\{\begin{array}{c}
u_{d}=R_{s} i_{d}+L_{s} \frac{d i_{d}}{d t}-\omega L_{s} i_{q} \\
u_{q}=R_{s} i_{q}+L_{s} \frac{d i_{q}}{d t}+\omega L_{s} i_{d}+\omega \lambda_{m}
\end{array}\right.
$$

The flux linkage was obtained by the product of the inductance matrix of the motor and the current, as shown in Equation (9):

$$
\lambda=\left(\begin{array}{llll}
\lambda_{f} & \lambda_{a} & \lambda_{b} & \lambda_{c}
\end{array}\right)^{T}=\left[\begin{array}{llll}
L_{f f} & L_{a f} & L_{b f} & L_{c f} \\
L_{a f} & L_{a a} & L_{a b} & L_{c a} \\
L_{b f} & L_{a b} & L_{b b} & L_{b c} \\
L_{c f} & L_{c a} & L_{b c} & L_{c c}
\end{array}\right]\left[\begin{array}{c}
i_{f} \\
i_{a} \\
i_{b} \\
i_{c}
\end{array}\right]
$$


where $L$ is the inductance matrix of the motor; the conversion matrix between the 3-phase current and $d$ axis and $q$ axis currents is given by Equation (10):

$$
C=\sqrt{\frac{2}{3}}\left[\begin{array}{ccc}
\sqrt{\frac{3}{2}} & 0 & 0 \\
0 & \cos \theta & \sin \theta \\
0 & \cos \left(\theta-\frac{2 \pi}{3}\right) & \sin \left(\theta-\frac{2 \pi}{3}\right) \\
0 & \cos \left(\theta+\frac{2 \pi}{3}\right) & \sin \left(\theta+\frac{2 \pi}{3}\right)
\end{array}\right]
$$

Then, the motor flux linkage equation was converted into:

$$
\left[\begin{array}{c}
\lambda_{f} \\
\lambda_{d} \\
\lambda_{q}
\end{array}\right]=\left[\begin{array}{ccc}
L_{f} & 3 / 2 L_{m} & 0 \\
L_{m} & L_{s} & 0 \\
0 & 0 & L_{s}
\end{array}\right]\left[\begin{array}{l}
i_{f} \\
i_{d} \\
i_{q}
\end{array}\right]
$$

where, $\lambda_{m}=L_{m} i_{f}$ is the flux linkage generated by the magnetic field of the rotor permanent magnet in the stator winding. The magnetic energy $W$ stored in the coil was calculated by Equation (12):

$$
W=1 / 2\left(\begin{array}{lll}
i_{f} & i_{d} & i_{q}
\end{array}\right)\left(\begin{array}{lll}
\lambda_{f} & \lambda_{d} & \lambda_{q}
\end{array}\right)^{T}
$$

If the motor rotor deviated slightly from the balance position $g_{0}$ in the axial direction, the magnetic energy changed accordingly. Therefore, the axial magnetic force and torque were calculated by the partial derivative of the magnetic energy in the axial displacement $g$ and rotation direction $\theta$ [21]. The axial electromagnetic force between the motor stator and rotor is:

$$
F_{m 0}=-\frac{\partial W}{\partial g}=\frac{1}{2 g^{2}}\left[L_{f}^{\prime} i_{f}^{2}+\frac{5}{2} L_{m}^{\prime} i_{d} i_{f}+\frac{3}{2} L_{a a 0}^{\prime}\left(i_{d}^{2}+i_{q}^{2}\right)\right]
$$

Additionally, the torque $T_{s}$ was expressed as:

$$
T_{s}=\frac{3}{2} p\left(\lambda_{d} i_{q}-\lambda_{q} i_{d}\right)=\frac{3 p L_{m}^{\prime} i_{f} i_{q}}{2 g}
$$

\subsection{Axial Force Modeling of the Permanent Magnet Bearing}

The magnetic field of permanent magnetic bearing was solved by the static magnetic field. The permanent magnetic force was obtained by integrating the Maxwell stress tensor on the surface of a permanent magnetic bearing [22]. The calculation formula used was:

$$
f_{p}=n \cdot T=-\frac{1}{2} n(H \cdot B)+(n \cdot H) B^{T}
$$

where $n$ is the outward normal vector of the outer surface of the permanent magnet bearing and $T$ is the Maxwell stress tensor on the outer surface of the permanent magnet bearing. The axial component $f_{z}$ of the permanent magnetic force $f_{p}$ is the axial force of the permanent magnetic bearing on the rotor, and the direction is vertical upward along the $z$ axial direction. Its derivative relative to the axial displacement is the magnetic stiffness [23], which was defined as:

$$
k_{z 1}=\frac{d f_{z}}{d z}=\frac{f\left(z_{k}\right)-f\left(z_{k+1}\right)}{z_{k+1}-z_{k}}
$$

The three-dimensional model of the permanent magnet bearing assembly was established, and the schematic diagram is shown in Figure 5. The upper concentric magnetic rings were arranged on the blood pump casing, which were static magnetic rings. The lower concentric magnetic rings were arranged on the upper-end face of the impeller and were movable magnetic rings. 


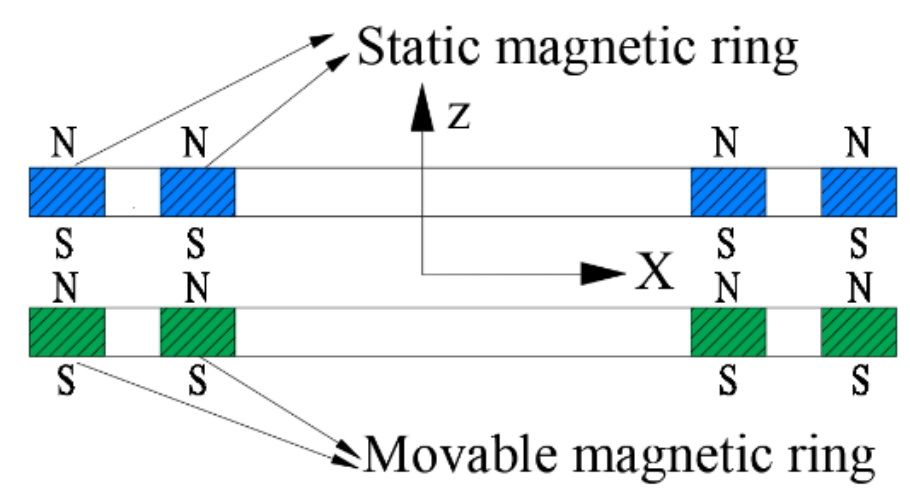

Figure 5. Structure composition of the permanent magnet bearing.

The material of the permanent magnetic bearing was the permanent, magnetic, rare earth material NdFeB35, which adopted an axial magnetization. The specific parameters of the permanent magnetic bearing are shown in Table 2.

Table 2. Material parameters of the permanent magnet bearing.

\begin{tabular}{cccc}
\hline Parameter & Symbol & Value & Unit \\
\hline Residual flux density & $B_{r}$ & 1.3 & $\mathrm{~T}$ \\
Coercivity & $H_{c}$ & 960 & $\mathrm{kA} / \mathrm{m}$ \\
Magnetic energy & $B H_{\max }$ & 40 & $\mathrm{MGOe}$ \\
\hline
\end{tabular}

The magnetic field of the permanent magnet bearing was solved by the static field module in the COMSOL software, and the magnetic force was obtained by integrating the Maxwell stress surface. When simulating the static magnetic field of the permanent magnet bearing, the axial air gap scanning range was set to $0.1 \sim 3.1 \mathrm{~mm}$. In the permanent magnet bearing, the movable magnetic ring was offset under the action of the external load and interference. Figure 6a shows the magnetic density and magnetic induction line distribution when the air gap $g_{1}$ was $0.4 \mathrm{~mm}$ and $1.72 \mathrm{~mm}(\Delta z=1.32 \mathrm{~mm})$. The air gap was inversely proportional to the magnetic density and the strength of the magnetic field. The variation law of the axial restoring force $F_{m 1}$ is shown in Figure $6 \mathrm{~b}$. There was a strong nonlinearity between the axial restoring force $F_{m 1}$ and the air gap $g_{1}$. The smaller the air gap between the movable magnetic ring and the static magnetic ring, the greater the axial magnetic force. The equilibrium position of the rotor was $g_{1}=1.6 \mathrm{~mm}$ and the movable range was $1.5-1.7 \mathrm{~mm}$. Within this range, the axial restoring force $F_{m 1}$ and axial offset were approximately linear. Therefore, the axial force was linearized near the equilibrium position to obtain the linearization model of the permanent magnet bearing.

The axial force at the different axial displacements was fitted, and the mathematical model between the axial force $F_{m 1}$ and the axial displacement $g_{1}$ was established, as shown in Equation (17). The root mean square error RMSE of the fitting results was 0.042 and the correlation coefficient $R$ was 0.999 :

$$
F_{m 1}=2.1 g_{1}^{3}-46.88 g_{1}^{2}+135.32 g_{1}^{1.5}-127.65 g_{1}+37.72
$$




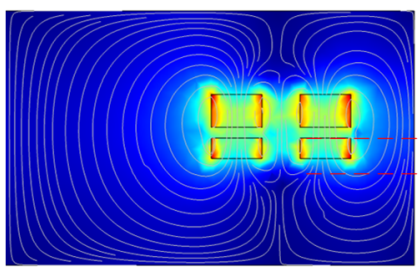

$g_{1}=0.4 \mathrm{~mm}$

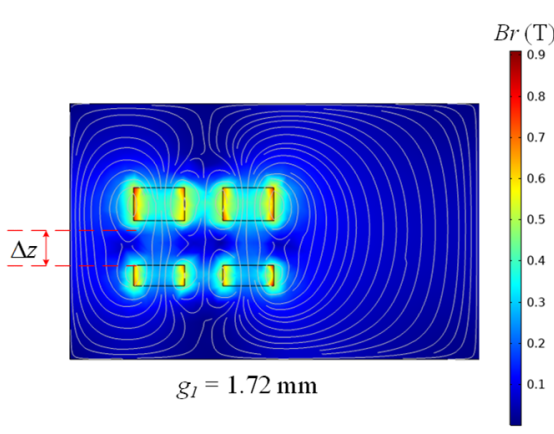

(a)

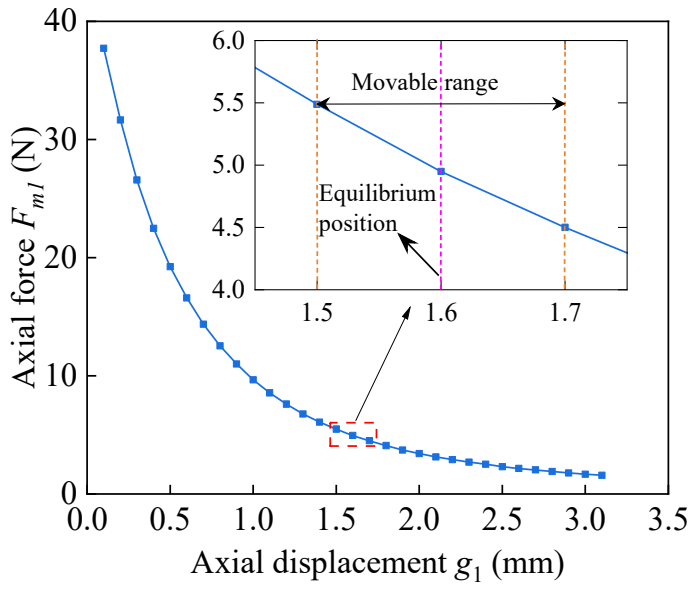

(b)

Figure 6. Variation law of the magnetic field and axial force during the axial offset: (a) Magnetic flux density and magnetic induction line distribution of the permanent magnet bearing; (b) Relationship curve between axial force and axial displacement.

\subsection{Model Linearization of Magnetic Suspension System}

Without considering the effects of fluid force, gravity and external disturbance, the total axial force on the rotor is given by Equation (18):

$$
F_{z}=F_{m 0}+F_{m 1}
$$

When the motor rotor is in a balanced and stable position, the air gap between the stator and the rotor surface is $g_{0}$. Assuming that the rotor has an axial offset $z$ and the rotor deviates from the blood pump inlet along the axial direction, the air gap becomes $g_{0}-z$. The axial force and electromagnetic torque applied to the rotor are linearized at the equilibrium point, and Equations (13) and (14) are expanded by the Lagrange linearization method, then the respective linearization models of axial force and torque are:

$$
\begin{gathered}
F_{z}=\frac{1}{2 g_{0}^{2}}\left[L_{f}^{\prime} i_{f}^{2}+\frac{5}{2} L_{m}^{\prime} i_{d} i_{f}+\frac{3}{2} L_{a a 0}^{\prime}\left(i_{d}^{2}+i_{q}^{2}\right)-9.92 g_{0}^{2}\right]-\frac{z}{2 g_{0}^{3}}\left[L_{f}^{\prime} i_{f}^{2}+\frac{5}{2} L_{m}^{\prime} i_{d} i_{f}+\frac{3}{2} L_{a a 0}^{\prime}\left(i_{d}^{2}+i_{q}^{2}\right)-9.6 g_{0}^{3}\right] \\
T_{l}=\frac{3 p L_{m}^{\prime} i_{f} i_{q}}{2 g_{0}}\left(1-\frac{z}{g_{0}}\right)
\end{gathered}
$$

The air gap $g_{0}$ of the motor was $1.8 \mathrm{~mm}$. Due to structural constraints, the maximum displacement on one side of the rotor was $0.1 \mathrm{~mm}$ and the axial displacement $z$ was relatively small during the actual axial position control of the rotor. Therefore, $z / g_{0}$ was approximately 0. In addition, $k_{t}=3 p L^{\prime}{ }_{m} i_{f} / 2 g_{0}$ instead of the constant term in Equation (20), Equation (20) is simplified as:

$$
T_{l}=k_{t} i_{q}
$$

According to Equation (19), the axial force $F_{z}$ was coupled by the direct axis current $i_{d}$ and the quadrature axis current $i_{q}$. If the coupling term is ignored, the axial force is only related to $i_{d}$ and can be controlled linearly. According to Equation (21), the electromagnetic torque is only related to the quadrature axis current $i_{q}$. After linearization, the axial force shown in Equation (19) can be expressed as in the form of $z$ and $i_{d}$ as:

$$
F_{z}=K_{i} i_{d}+K_{z} z+f
$$

where, $K_{i}=5 L_{m}^{\prime} i_{f} / 4 g_{0}^{2}$ is the force gain; $K_{z}=\left[L_{f}^{\prime} i_{f}^{2}+2.5 L_{m}^{\prime} i_{f} i_{d}+1.5 L_{a a 0}^{\prime}\left(i_{d}^{2}+i_{q}^{2}\right)-9.6 g_{0}^{3}\right] / 2 g_{0}^{3}$ is the axial displacement stiffness; other terms of the model can be regarded as distur- 
bance terms, that is, $f=\left[L_{f}^{\prime} i_{f}^{2}+1.5 L_{a a 0}^{\prime}\left(i_{d}^{2}+i_{q}^{2}\right)-9.92 g_{0}^{2}\right] / 2 g_{0}^{2}$. When the impeller was passively suspended in the equilibrium position, $f$ is $0 \mathrm{~N}$. Without considering gravity and fluid force, according to Newton's second law of motion, the axial motion of rotor can be expressed as:

$$
m \ddot{z}-K_{z} z=K_{i} i_{d}+f
$$

According to Equation (23), it can be seen that the rotor of the bearingless motor exhibited a negative stiffness in the axial direction, which is unstable for the rotor suspension state and seriously affects the stable operation of the blood pump.

\subsection{Parameter Identification of the Magnetic Suspension System}

In order to establish an accurate motor suspension force and torque model, the motor parameters were obtained by parameter identification, and the parameters in the suspension force and torque model were calculated. Figure 7 shows the bearingless motor parameter identification platform, which adjusted the air gap between the rotor and stator by changing the position of the sliding table. The sliding table displacement was measured by the spectral confocal displacement sensor: the sensor probe was fixed on the fine-tuning platform; the probe was fixed through the fine-tuning platform and adjusted to the measurement range. Subsequently, the change in the air gap was calculated by measuring the sliding distance of the sliding table in real time. The displacement sensor mode was IFC2461(Micro-Epsilon Co. Ltd., Ortenburg, Germany), the measurement frequency was $25 \mathrm{kHz}$, the absolute error was less than $0.05 \%$ and the resolution was $0.004 \%$, which helped to realize the micron precision measurement of displacement. The motor, displacement sensor and motor controller were powered by a DC-regulated power supply. The power supply model was ITECH6322 and the voltage accuracy was $1 \mathrm{mV}$. The voltage of the motor and displacement sensor was $24 \mathrm{~V}$ and the power supply voltage of motor controller was $5 \mathrm{~V}$.

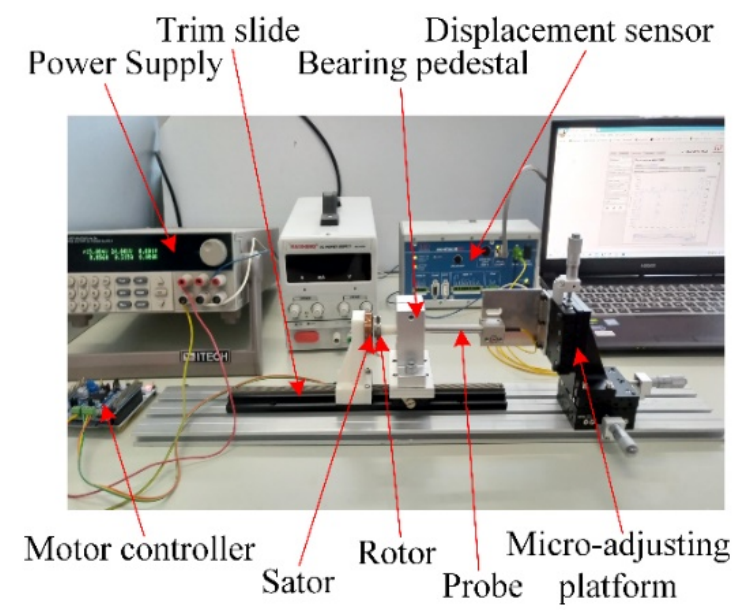

Figure 7. Parameter identification platform of the bearingless motor.

The position of the sliding table was adjusted, so that the air gap between the motor stator and rotor was $1.8 \mathrm{~mm}$, and the rotor position was fixed. The power supply was turned on and the voltage was adjusted. The motor parameters were identified through the motor controller and multiple experiments were conducted. The motor parameter identification results are shown in Table 3. 
Table 3. Motor parameter identification results.

\begin{tabular}{cccc}
\hline Parameter & Symbol & Value & Unit \\
\hline Rated voltage & $V_{b u s}$ & 24 & $\mathrm{~V}$ \\
Rated current & $I$ & 1.8 & $\mathrm{~A}$ \\
Rated speed & $\omega$ & 4500 & $\mathrm{rpm}$ \\
Armature winding & $R_{s}$ & 1.49 & $\Omega$ \\
Winding inductance & $L_{S}$ & 0.72 & $\mathrm{mH}$ \\
Polar pairs & $p$ & 4 & - \\
Flux linkage of permanent & $\lambda_{m}$ & $2.81 \times 10^{-3}$ & $\mathrm{~Wb}$ \\
magnet & $J$ & $4.5 \times 10^{-6}$ & $\mathrm{~kg} \cdot \mathrm{m}^{2}$ \\
Moment of inertia & $B$ & $2.05 \times 10^{-5}$ & $\mathrm{~N} \cdot \mathrm{s} / \mathrm{m}$ \\
\hline Damping coefficient & & &
\end{tabular}

Through the motor parameters, the axial force and torque of the motor was calculated, and the model parameters are $L_{a a 0}^{\prime}=8 \times 10^{-7} \mathrm{Hm}$, the leakage inductance $L_{a l}=5.3 \times 10^{-5} \mathrm{H}$; $L^{\prime}{ }_{m} i_{f}=4.88 \times 10^{-6} \mathrm{Ahm}$ and the torque parameter $k_{t}=1.63 \times 10^{-2} \mathrm{~N} \cdot \mathrm{m} / \mathrm{A}$.

\subsection{Verification of the Magnetic Suspension System Theoretical Model}

The transient electromagnetic field of the bearingless motor was solved using the ANSYS Electronics software. The rotor backplate was made of titanium alloy. The permanent magnet material was NdFeB35, the residual magnetic flux density $B_{r}$ was set to $1.3 \mathrm{~T}$, and the different magnetization directions were set according to the magnetic pole orientation. The material of the stator winding was copper and the number of turns was 115 . The material of the iron core and yoke was silicon steel. The number of turns and sinusoidal current excitation were set for the coil. The AC current excitation amplitude $i_{m}$ was $0.4 \mathrm{~A}$ and the spatial phase difference was 120 degrees. The electromagnetic field solution time was set to $10 \mathrm{~ms}$, and the simulation solution time step was the time corresponding to each $1^{\circ}$ rotation of the motor.

The axial force received by the rotor of the bearingless motor during rotation is shown in Figure 8a. The axial force obtained by the FEM simulation fluctuated all the time during the rotation process, and the amplitude was essentially within $0.5 \mathrm{~N}$. The axial force was negative, indicating that the motor rotor was always subject to the suction of the stator. The average axial force was calculated by FEM to be $-5.2 \mathrm{~N}$. Assuming that the rotor had no axial offset, the direct axis current $i_{d}$ was $0 \mathrm{~A}$ and the quadrature axis current $i_{q}$ was $0.4 \mathrm{~A}$; the axial force calculated by the theoretical model was $-4.63 \mathrm{~N}$. The two results were close, and the error of the theoretical model was $11 \%$. The variation process of the electromagnetic torque during the motor rotation is shown in Figure 8b. There is an obvious pulsation phenomenon of the rotor torque during rotation. The potential causes of torque ripple were the interactions of the stator and rotor magnetic field, current commutation, the cogging effect, and the armature reaction. The average value of the electromagnetic torque in the FEM simulation results was $6.6 \mathrm{~N} \cdot \mathrm{mm}$. According to the theoretical Equation (21), the theoretical torque at $3000 \mathrm{rpm}$ was $6.5 \mathrm{~N} \cdot \mathrm{mm}$, and the error was $1.5 \%$. The two values were very close, which verified the accuracy of the motor torque theoretical model.

When the motor rotor was offset under the action of external disturbance, the changes in the permanent magnetic force on the rotor are shown in Figure 9a. Because the motor structure and the permanent magnet bearings were spatially symmetrical, the permanent magnetic force in the $x$ and $y$ direction was always $0 \mathrm{~N}$, when the impeller was offset, and the axial force $F_{z}$ changed with the offset. When the impeller was offset to the inlet of the blood pump, the axial force on the impeller was upward, that is, the axial force direction was consistent with the offset direction, and its amplitude increased with an increase in the offset. Therefore, the impeller was unstable in the axial direction. The resultant axial force at the balance point was close to $0 \mathrm{~N}$. 


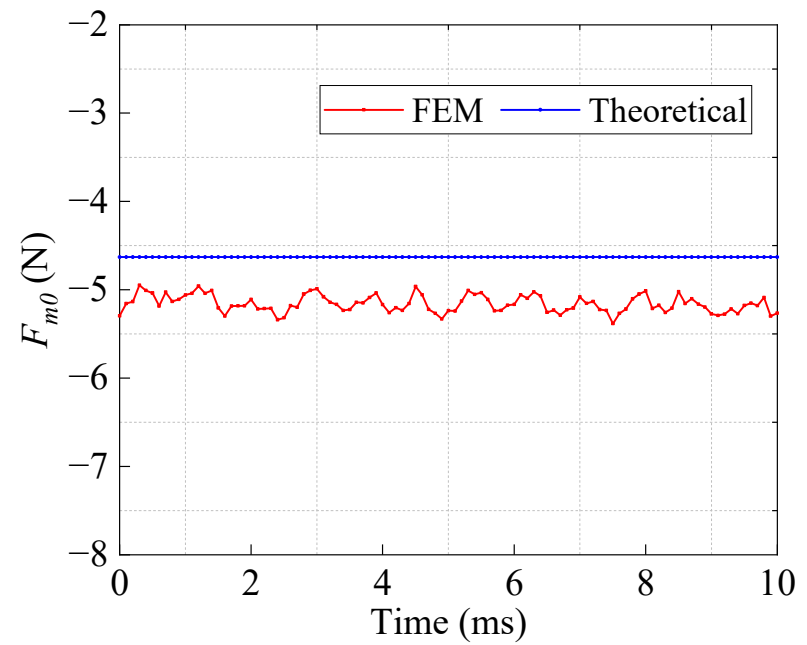

(a)

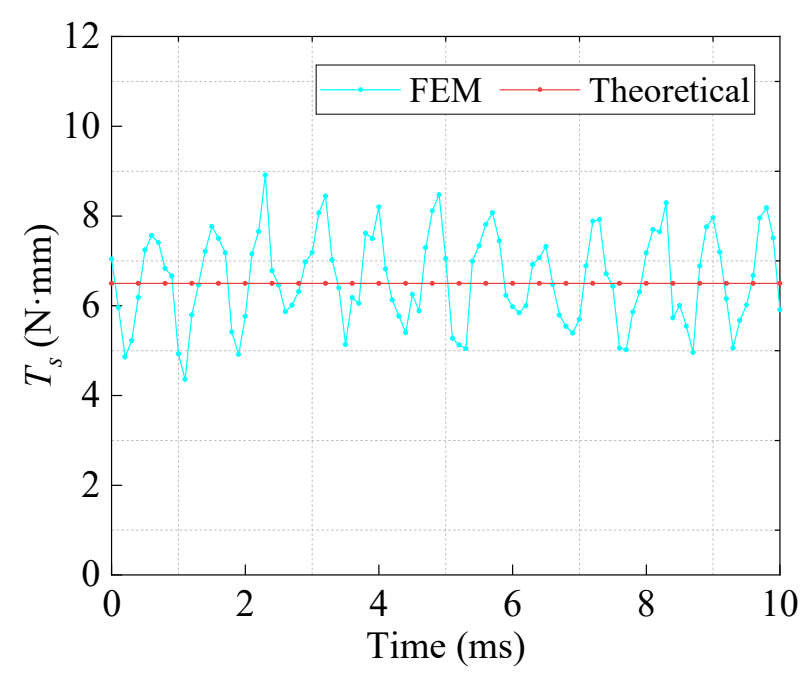

(b)

Figure 8. Variation curve of the electromagnetic torque and axial force during motor rotation: (a) Axial force of the bearingless motor; (b) Electromagnetic torque of the bearingless motor.

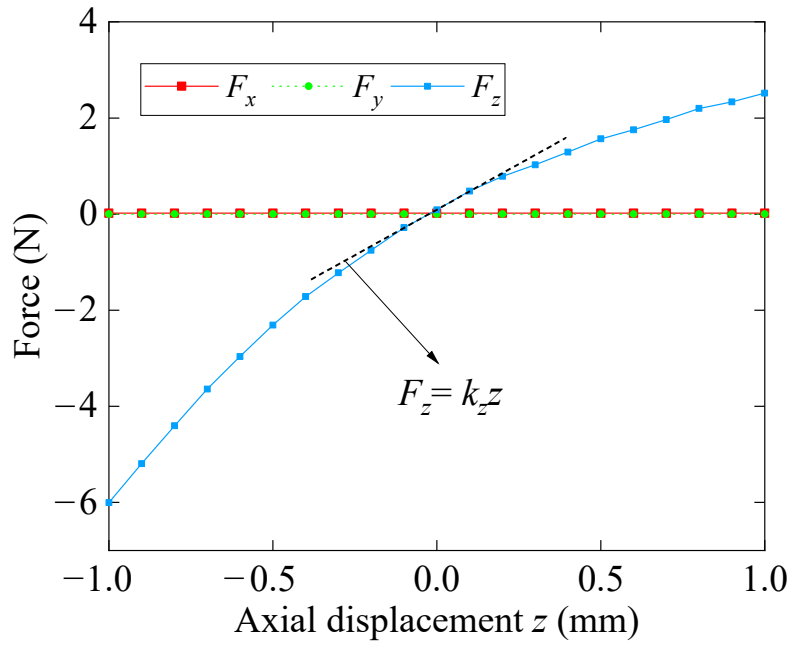

(a)

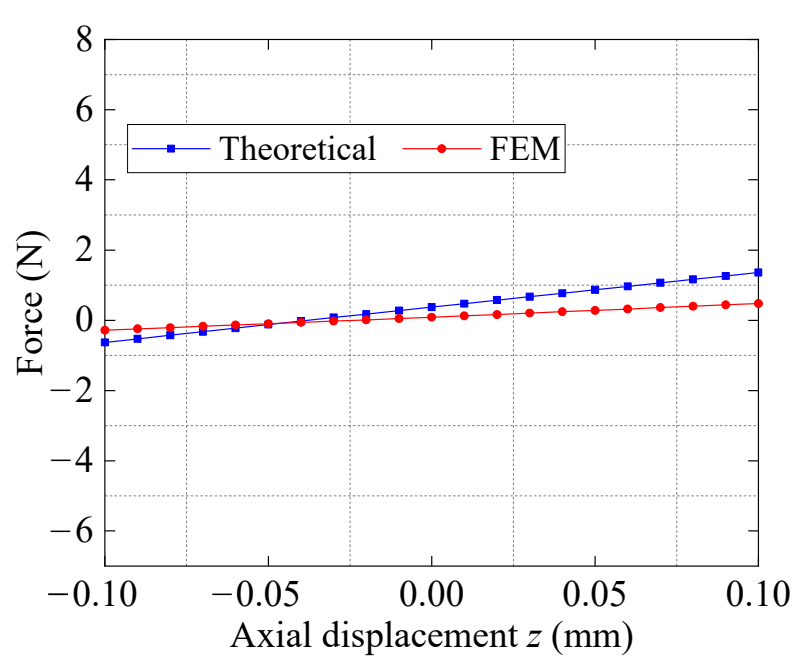

(b)

Figure 9. Relationship curve between the permanent magnetic force and the impeller displacement: (a) Variation law of the permanent magnetic force under axial displacement; (b) Variation curve of axial stiffness with axial displacement.

Figure $9 \mathrm{~b}$ shows the theoretical value and the FEM simulation results of the axial force of the rotor within the axial movable range. It can be seen from Figure $9 b$ that the theoretical value of axial force was very close to the FEM simulation results, which verifies the accuracy of the theoretical model. Thus, the stiffness calculated by the theoretical model can be used as a reference index for the structural design of the hydrodynamic bearing. The position where the resultant force was $0 \mathrm{~N}$ was located below the theoretical equilibrium point. Furthermore, the linear relationship between the axial force and the axial displacement at the equilibrium point also verified the rationality of the linearization of the axial force theoretical model. According to the definition of stiffness, the axial stiffness was negative, which indicated that the impeller was unstable under the action of external disturbance.

\subsection{Hydrodynamic Force and Stiffness Model of Hydrodynamic Bearing}

The hydrodynamic bearing was located on the inner cavity surface of the upper and lower casings of the blood pump. The fluid force generated by the dynamic pressure 
effect acted on the rotor to realize the axial stable suspension. Due to the secondary flow field at the upper and lower clearance of the blood pump, the blood flow field was in a spiral form. Although the herringbone groove hydrodynamic bearing had a better stability, the groove type was inconsistent with the blood flow form. When the blood flowed through the hydrodynamic bearing, flow separation and turbulence occurred, which could easily damage the blood. Therefore, in order to obtain a better blood compatibility, the hydrodynamic bearing was designed in the form of a spiral groove. The specific structure is shown in Figure 10a. The groove type of the hydrodynamic bearing is spiral. According to the rotation direction of the impeller and the flow direction of blood, the hydrodynamic bearing on the lower pump casing was designed as the "Pump-in" type, and the hydrodynamic bearing on the upper casing was designed as the "Pump-out" type. The structural parameters of the two hydrodynamic bearings were consistent. The inlet of the hydrodynamic bearing was located outside the spiral groove with radius $r_{s}$. When the impeller rotated in the direction shown in Figure 10a, the high-pressure fluid emitted by the impeller flowed into the hydrodynamic bearing from the inlet of the spiral groove. As the groove width of the spiral groove decreased in the flow direction, the wedge-shaped spiral groove formed a dynamic pressure effect, resulting in the bearing capacity to realize the suspension of the impeller. Figure $10 \mathrm{~b}$ shows the cross-sectional view of the hydrodynamic bearing. The vertical distance between the lower surface of the impeller and the pump casing is the liquid film thickness $h_{1}$ of the hydrodynamic bearing, that is, the suspension clearance of the impeller. The groove depth of the spiral groove of the hydrodynamic bearing is $h_{2}$, and the sum of $h_{1}$ and $h_{2}$ is the distance $h$ between the bottom surface of the impeller and the groove depth. The liquid film thickness $h_{1}$ did not only affect the suspension performance of the hydrodynamic bearing, but also affected the hemolysis performance. Therefore, the liquid film thickness was designed after comprehensively considering the performance of the hemolysis and suspension. Here, this factor is not considered temporarily in the structural design of the hydrodynamic bearing, and only the influence of the groove depth $h_{2}$ on the suspension performance was analyzed. In addition to the groove depth, the groove number $N$, the groove width ratio $\delta=B_{g} / B$ and spiral angle $\beta$ were the key parameters affecting the hydrodynamic bearing performance.

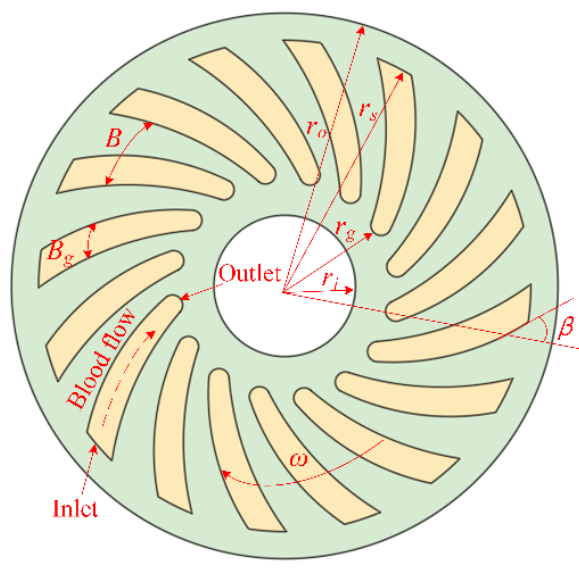

(a)

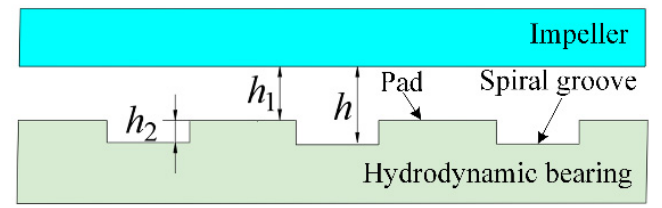

(b)

Figure 10. Structure composition of the hydrodynamic bearing: (a) Structural parameters of the hydrodynamic bearing; (b) Cross-sectional view of the hydrodynamic bearing.

The spiral groove of the hydrodynamic bearing was in the form of a logarithmic spiral, and its structural shape was closely related to the spiral angle $\beta$, which is expressed as:

$$
r=r_{g} e^{\theta \tan \beta}
$$


where, $r_{g}$ is the base circle radius of spiral line, $\theta$ is the spiral line control angle, and $\beta$ is the spiral angle. If the pressure change in the clearance direction was ignored, the liquid film pressure distribution of the hydrodynamic bearing could be solved based on the Reynolds equation in lubrication theory. The steady-state Reynolds equation is shown in Equation (25):

$$
\nabla_{t} \cdot\left(\rho h_{1} v_{a v e}\right)=0
$$

where, $\rho$ is the fluid density, $h_{1}$ is the clearance, $h_{1}=h_{c}+h_{b}, h_{c}=-\boldsymbol{u}_{c} \cdot \boldsymbol{n}_{r e f}, h_{b}=h_{b 1}+\boldsymbol{u}_{b} \cdot \boldsymbol{n}_{r e f}$ $-\boldsymbol{u}_{b} \cdot \nabla_{t} h_{b 1}, \boldsymbol{u}_{c}$ is the impeller displacement, $n_{r e f}$ is the reference normal direction, $h_{b 1}$ is the initial clearance, $v_{\text {ave }}$ is the average speed, and the calculation formula is:

$$
v_{\text {ave }}=\frac{1}{2}\left(v_{c, t}+v_{b, t}\right)-\frac{h_{1}}{12 \mu} \nabla_{t} p_{f}
$$

where $\mu$ is blood viscosity; $v_{c, t}$ and $v_{b, t}$ are the velocity vectors of the impeller surface and hydrodynamic bearing wall at the clearance, respectively. The specific calculation method is shown in Equations (27) and (28):

$$
\begin{gathered}
v_{c, t}=\left(I-n_{r e f} \otimes n_{r e f}\right)\left\{\dot{u}_{c .}+\Omega \times\left(X-X_{c}\right)\right\} \\
v_{b, t}=\left(1-n_{r e f} \otimes n_{r e f}\right) \dot{u}_{b}
\end{gathered}
$$

The absolute pressure $p_{A}$ at any point on the bearing surface was calculated from the sum of the reference pressure $p_{r e f}$ and the relative pressure $p_{f}$, which is $p_{A}=p_{r e f}+p_{f}$. The pressure distribution on the whole hydrodynamic bearing surface was obtained through an iterative calculation. The pressure of each node on the hydrodynamic bearing surface was double integrated along the radial direction and circumferential direction to obtain the bearing capacity $F_{f}$ of the liquid film:

$$
F f=\iint_{r_{i}}^{r_{o}} p_{A} r d r d \theta
$$

where, $r_{i}$ and $r_{o}$ are the inner radius and outer radius of the hydrodynamic bearing, respectively. When the axial displacement of the impeller occurred, the clearance between the impeller and the hydrodynamic bearing changed correspondingly, as did the bearing capacity imposed by the hydrodynamic bearing on the impeller. The change rate is the stiffness of the hydrodynamic bearing, which represents the repulsion of the hydrodynamic suspension bearing to the disturbance, which is defined as:

$$
K_{f}=\frac{d F f}{d \Delta h_{1}}
$$

\subsection{Axial Suspension Stability Analysis of Magnetic-Hydrodynamic Hybrid Suspension System}

In order to eliminate the negative stiffness of the magnetic suspension system and realize the stable suspension in the axial direction, the hydrodynamic bearing is required to provide stable support for the rotor, eliminate the negative stiffness and ensure that the rotor has a certain passive suspension stability under the action of external disturbance. The stiffness and damping characteristics of the hydrodynamic bearing can effectively limit the axial movement and amplitude of the rotor vibration. Therefore, based on the dynamic model of the magnetic suspension system, it was also necessary to include the model parameters related to the action of the hydrodynamic bearing and the flow field, in order to establish the dynamic model of the rotor under the action of the magnetic field, flow field, gravity and external disturbance. The hydrodynamic performance was optimized through passive suspension stability analysis, in order to improve the suspension stability 
of the blood pump and reduce the power consumption of the blood pump motor. The axial dynamic model of the rotor is shown in Equation (31):

$$
m \ddot{z}+C_{f} \dot{z}+\left(K_{f}-K_{z}\right) z=0
$$

where $m$ is the rotor mass, $C_{f}$ is the damping of the hydrodynamic bearing and $K_{f}$ is the stiffness of the hydrodynamic bearing. The stiffness $K_{f}$ and damping $C_{f}$ were similar to the active regulation of impeller spatial position through the PD controller, and their values determined the stability of the suspension system. According to Equation (31), the damping coefficient $C_{f}>0$; therefore, the prerequisite for the system stability was $K_{f}-\mathrm{K}_{\mathrm{z}}>0$; the axial stiffness amplitude of the hydrodynamic bearing was greater than that of the magnetic suspension system, and the greater the difference between the two stiffnesses, the more stable the system. For the passive suspension stability, the motor current $i_{d}$ and $i_{q}$ were both $0 \mathrm{~A}$. Therefore, according to the calculation formula of $k_{z}$, the axial stiffness $k_{z}$ of magnetic suspension system was $-2547 \mathrm{~N} / \mathrm{m}$. Since the hydrodynamic bearing is symmetrically arranged on the inner cavity surface of the upper and lower pump casings, when analyzing the suspension stability, the suspension stability was guaranteed only if the stiffness of the one-sided hydrodynamic bearing was greater than $-1274 \mathrm{~N} / \mathrm{m}$.

\section{Stiffness Analysis and Structural Design of the Hydrodynamic Bearing}

The parameters of the hydrodynamic bearing mainly included the groove number $N$, spiral angle $\beta$, groove width ratio $\delta$ and groove depth $h_{2}$. The effects of different structural parameters on the stiffness and hydrodynamic force were studied to obtain the best combination of the structural parameters. The inlet and outlet pressures of the hydrodynamic bearing were $82 \mathrm{mmHg}$ and $48 \mathrm{mmHg}$, respectively, and the impeller speed was $2600 \mathrm{rpm}$. The blood viscosity was $3.5 \mathrm{mPa} \cdot \mathrm{s}$ and the density was $1055 \mathrm{~kg} \cdot \mathrm{m}^{3}$. Figure 11 shows the solution results of the pressure distribution on the surface of the hydrodynamic bearing. The pressure distribution was uniform and the blood pressure in the spiral groove was relatively high. When the blood from the impeller flowed through the spiral groove of the hydrodynamic bearing, its pressure decreased continuously, and the bearing capacity was formed through the dynamic pressure effect in the wedge gap to realize the suspension of the impeller.

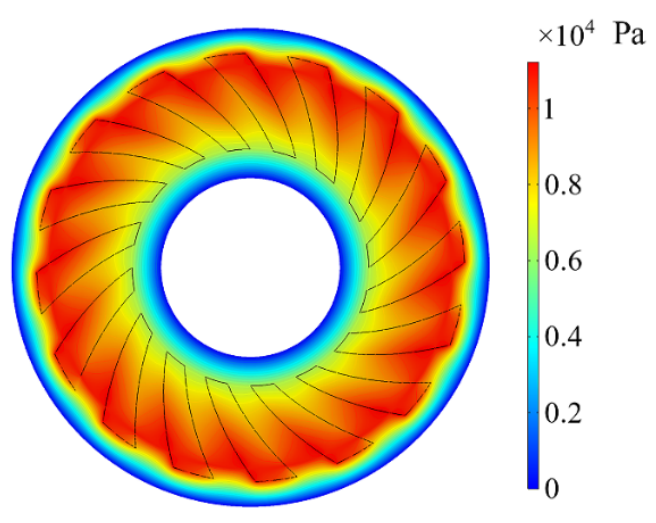

Figure 11. Pressure distribution of the hydrodynamic bearing surface.

The radial pressure distribution of the hydrodynamic bearing is shown in Figure 12a. When the blood flowed from the pad edge of the hydrodynamic bearing into the spiral groove, the blood pressure increased continuously, the blood maintained a large pressure in the spiral groove, and the dynamic pressure effect was strong. When the blood flowed out of the spiral groove to the edge of the pad, the blood pressure decreased continuously. It can be seen from Figure 12b that when the groove width ratio $\delta$ was 0.5 , the blood pressure first increased and later decreased along the rotation direction in the circumferential direction. However, the blood pressure at the spiral groove was higher than that in the pad area, 
indicating that there was an obvious dynamic pressure effect of the spiral groove, which helped to provide a large bearing capacity for the impeller. In addition, according to the pressure distribution diagram of the hydrodynamic bearing, the pressure clearly changed at the junction of the spiral groove and the pad.

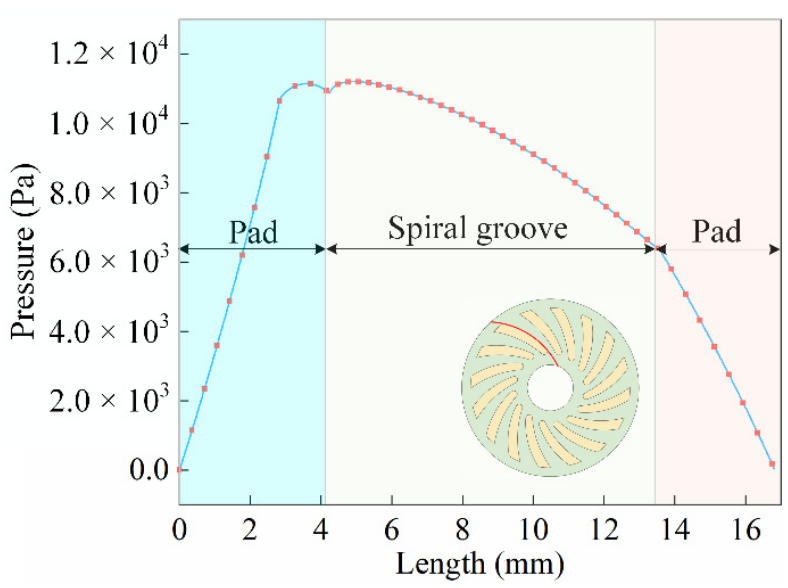

(a)

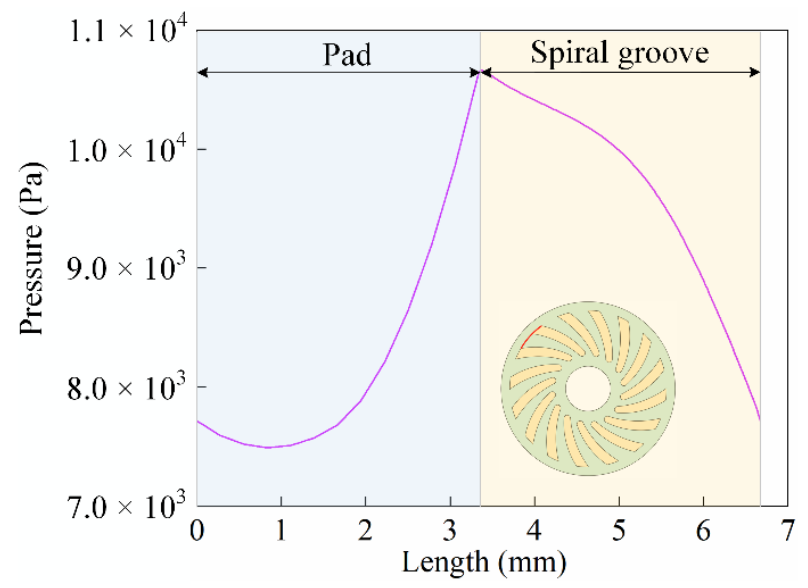

(b)

Figure 12. Pressure distribution of the hydrodynamic bearing: (a) Radial pressure distribution; (b) Circumferential pressure distribution.

It can be seen from Figure 13a that the greater the number of grooves, the greater the dynamic pressure effect on the spiral groove. Accordingly, the hydrodynamic force of the hydrodynamic bearing was higher, and its range was from 7.25-7.36 N. The stiffness $K_{f}$ also increased with the increase in the number of grooves, and the stiffness range was from $2300-3900 \mathrm{~N} / \mathrm{m}$, greater than the critical stiffness value of $-1274 \mathrm{~N} / \mathrm{m}$. Therefore, in order to achieve a stable suspension, a higher number of grooves in the hydrodynamic bearing offered a better suspension performance. The influence of the groove depth on the stiffness and hydrodynamic force is shown in Figure 13b. The hydrodynamic force increased with an increase in the groove depth $h_{2}$. The stiffness first increased and then decreased with an increase in the groove depth $h_{2}$, and the stiffness range was $2450-4000 \mathrm{~N} / \mathrm{m}$. It can be seen from the stiffness curve that, in order to obtain a high axial stiffness $K_{f}$, the range of the groove depth $h_{2}$ was around $0.06 \mathrm{~mm}$. If it was considered to obtain high stiffness $K_{f}$, while ensuring high axial hydrodynamic force, the groove depth was set to about $0.1 \mathrm{~mm}$.

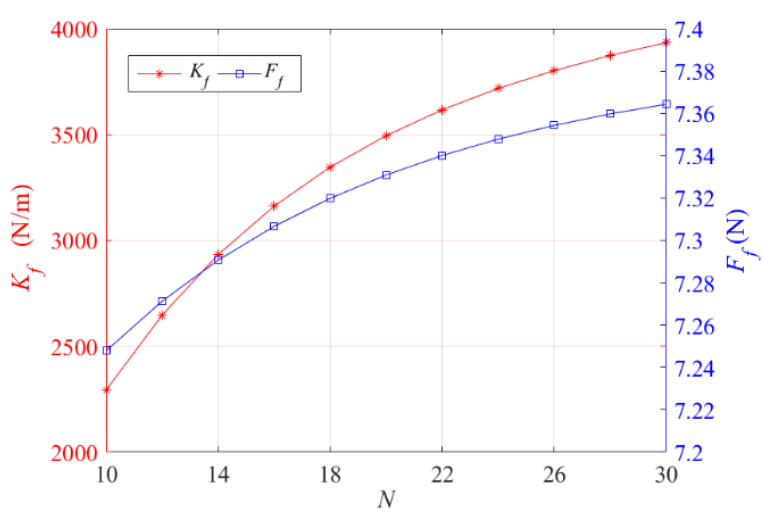

(a)

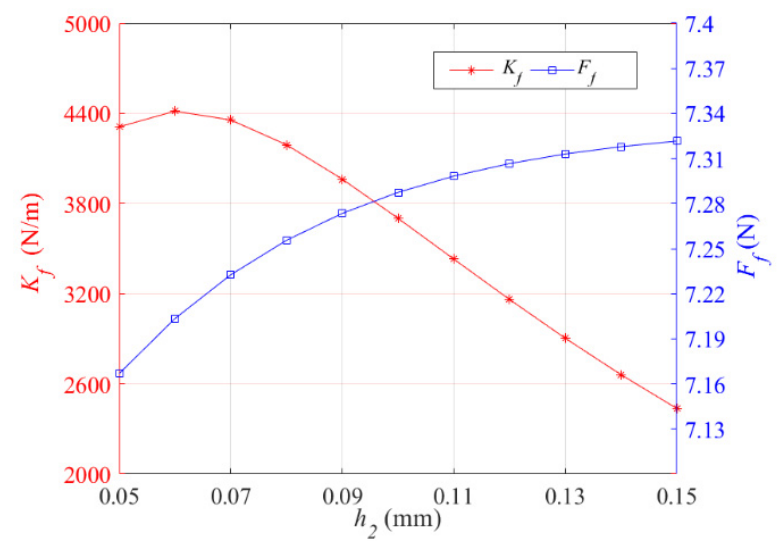

(b)

Figure 13. Influence of the groove number and groove depth on stiffness and hydrodynamic force: (a) Number of the spiral grooves; (b) Spiral groove depth. 
The influence of the groove width ratio $\delta$ on the stiffness and hydrodynamic force is shown in Figure 14a. When the groove width ratio is 0 and 1, the hydrodynamic bearing becomes a full pad and groove, and the dynamic pressure effect disappears. Therefore, a groove width ratio in the range from $0-1$ will maximize the hydrodynamic force. The selection range of groove width ratio was from 0.3-0.9. With the increase in the groove width ratio, the hydrodynamic force initially increased and later a decrease was observed. The groove width ratio with a peak hydrodynamic force was near 0.9 , but the stiffness decreased with an increase in the groove width ratio, and its value decreased from $3500 \mathrm{~N} / \mathrm{m}$ to $2060 \mathrm{~N} / \mathrm{m}$. Figure $14 \mathrm{~b}$ shows the variation law of the stiffness and hydrodynamic force with spiral angle. With a gradual increase in the spiral angle, the hydrodynamic force initially increased and then gradually decreased. The stiffness first increased followed by a decrease accompanied by an increase in the spiral angle, and its range decreased from $6000 \mathrm{~N} / \mathrm{m}$ to $5600 \mathrm{~N} / \mathrm{m}$. A high hydrodynamic force and axial stiffness was achieved when the spiral angle $\beta$ was $65^{\circ}$.

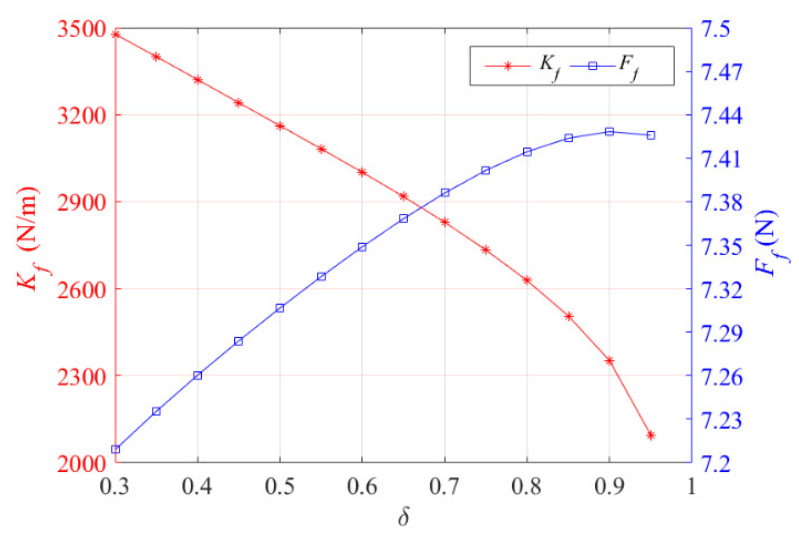

(a)

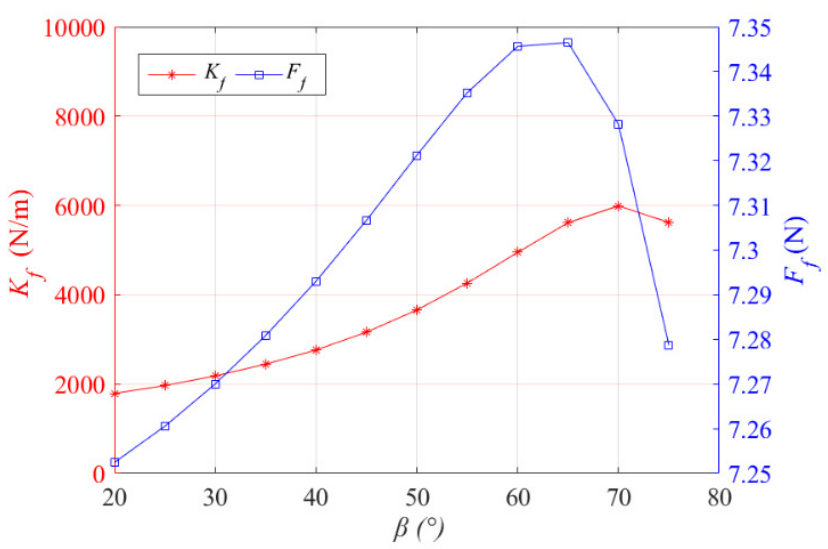

(b)

Figure 14. Influence of the groove width ratio and spiral angle on the stiffness and hydrodynamic force: (a) Groove width ratio; (b) Spiral angle.

From the above analysis, it can be seen that under different structural parameters, the hydrodynamic force was essentially between 7.17 and $7.43 \mathrm{~N}$ with little changes, while the stiffness range corresponding to different structural parameters of hydrodynamic bearing changed significantly. According to the variation law of each structural parameter pair, in order to obtain a relatively high axis stiffness, the number of grooves and the spiral angle should be as large as possible, and the groove depth and groove width ratio should be as small as possible. In order to ensure the stable suspension of the blood pump impeller under an external disturbance, the axial stiffness should be much higher than the axial negative stiffness of the bearingless motor. According to the hydraulic characteristics and the flow field distribution of the blood pump, based on the above structural parameters and stiffness analysis of the hydrodynamic bearing and considering the constraints of the structural dimensions of the blood pump, the structural parameters of the hydrodynamic bearing were designed as follows: the number of grooves was 20, the spiral angle was $45^{\circ}$, the groove width ratio was 0.5 and the groove depth was $0.1 \mathrm{~mm}$. The titanium alloy casing machined by CNC (Computerized Numerical Control) with the hydrodynamic bearing is shown in Figure 15. After calculation, the axial stiffness at $1800 \mathrm{rpm}$ was found to be $3819 \mathrm{~N} / \mathrm{m}$, which was much greater than the critical negative stiffness $-1274 \mathrm{~N} / \mathrm{m}$ of the magnetic suspension system. Therefore, the blood pump could also ensure the ability of stable suspension at high speeds. 


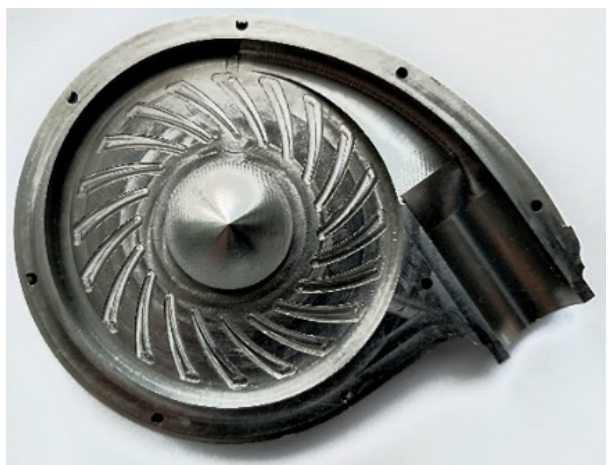

Figure 15. Processed blood pump casing with a hydrodynamic bearing.

\section{Experimental Validation of the Axial Passive Suspension Stability of the Blood Pump}

In order to simulate the interaction between the blood pump and the cardiovascular system and study the suspension stability of the blood pump during the auxiliary blood pumping, an experimental platform, used to imitate the circulatory loop, was built, as shown in Figure 16. The system consisted of a left atrial simulator, left ventricular simulator, aortic simulator, venous circuit pipeline, mitral valve, aortic valve and damping valve. The measurement module included a pressure sensor (PX409-015CGUSBH, \pm 1 bar, $0.06 \%$ accuracy, Omega Engineering Inc., Norwalk, CA, USA) and a displacement sensor IFC2461. The control module was composed of the left ventricular simulator controller and the blood pump controller. The measured pressure signal was transmitted to the computer through the communication interface. By controlling the motion of the left ventricular simulator, the contraction and relaxation of the ventricle were simulated to produce a pulsatile physiological blood flow. The blood pump controller controlled the rotation of the impeller according to the set target speed to realize the physiological blood perfusion. The mock circulatory loop could simulate the response of the blood pump to cardiac unloading and cardiovascular system at a constant speed and was used to study the influence of the time-varying disturbance generated by the cardiovascular system on the suspension state of the blood pump impeller.

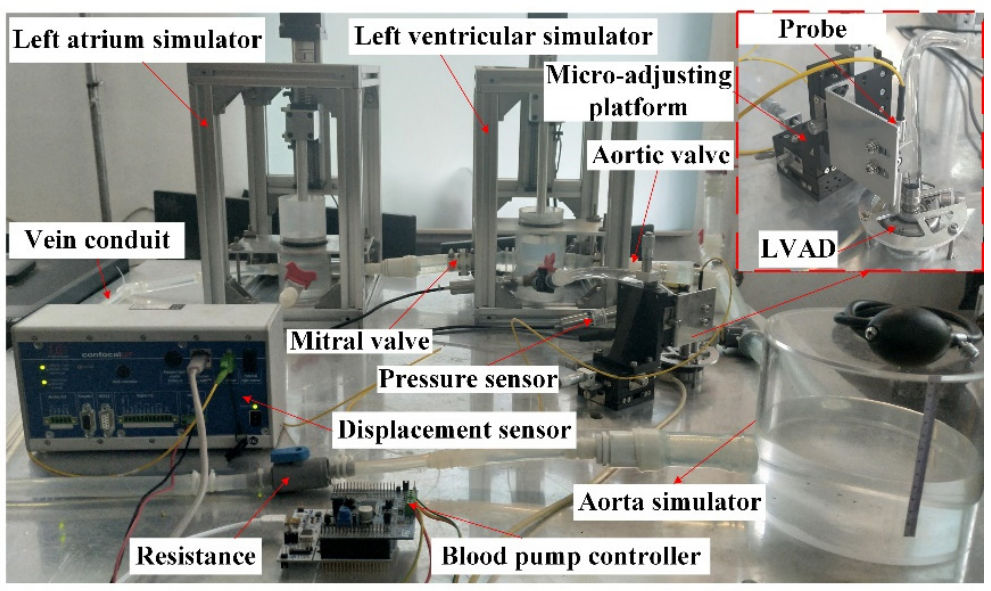

Figure 16. Extracorporeal mock circulatory loop.

The axial relative displacement of the impeller was measured by the spectral confocal displacement sensor, and the signal with high-frequency noise was filtered. The impeller position was set to $0 \mathrm{~mm}$, when the blood pump was not started, and the measured value of the sensor truly reflected the change in the axial suspension position of the impeller. It can be seen from Figure 17a that the impeller of the blood pump could realize 
the axial suspension at a low speed of $1800 \mathrm{rpm}$; the higher the speed, the greater the axial displacement.

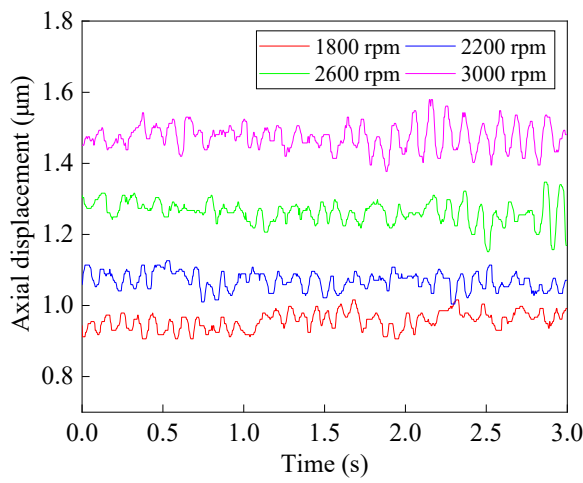

(a)

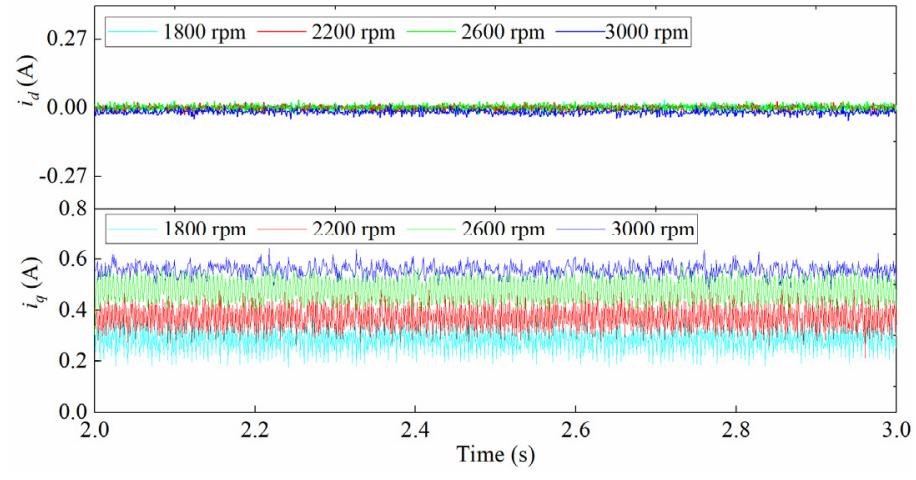

(b)

Figure 17. Axial displacement and current waveform corresponding to different rotating speeds of the blood pump impeller: (a) Axial displacement; (b) Current waveform.

Figure $17 \mathrm{~b}$ shows the $i_{d}$ and $i_{q}$ current waveforms corresponding to different rotating speeds of the blood pump. Since the study focused on the passive suspension stability of the blood pump, the $i_{d}$ was always maintained at $0 \mathrm{~A}$ through a closed-loop control, and the $i_{q}$ current increased with an increase in the rotating speed. When no active control was applied in the axial direction, the higher the speed, the more clear the dynamic pressure effect, and the greater the hydrodynamic force of the bearing. In addition, with the increase in the impeller speed, the flowrate of the blood pump and the impact force of the fluid on the impeller also increased. The above reasons made the axial displacement of the impeller larger, that is, the suspension clearance became larger. It was observed that the different speed changes exhibited little effect on the axial displacement, and the change range was $0.2 \mu \mathrm{m}$.

Figure 18 shows the hydraulic efficiency curve of the blood pump at different speeds and flowrates. It can be seen from the hydraulic efficiency curve that the speed and flowrate had a great impact on the hydraulic efficiency of the blood pump. The smaller the flow, the higher the speed, and the greater the hydraulic efficiency of the blood pump. When the blood pump impeller rotates at high speed, the dynamic pressure effect is more clear, the suspension stability is better and the hydraulic efficiency is higher.

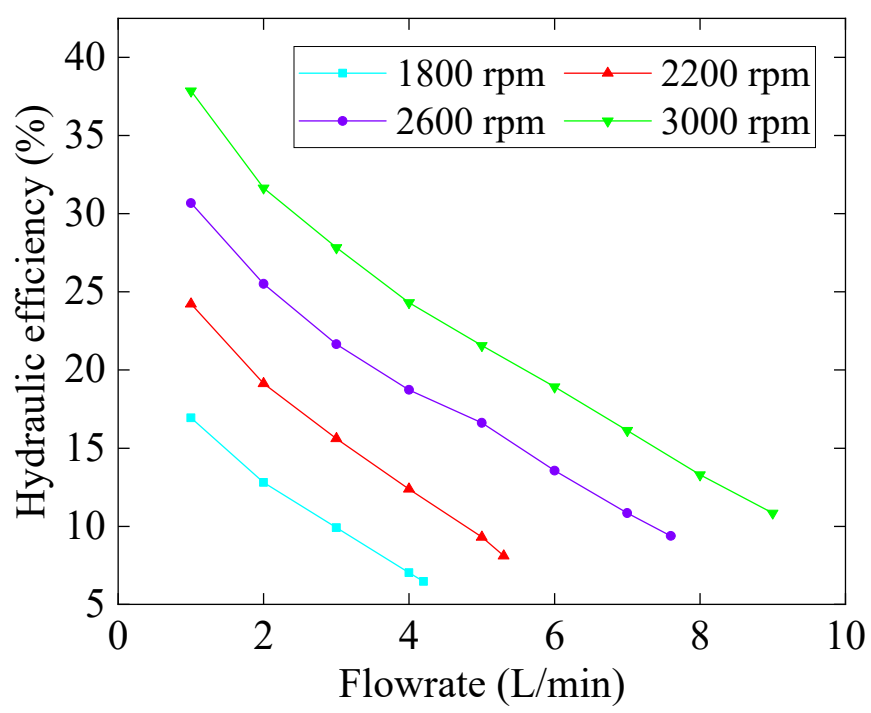

Figure 18. Hydraulic efficiency of blood pump corresponding to different speeds and flowrates. 
In the experimental validation of the mock circulatory loop works, the influence of the blood pumped by the failed heart on the suspension rotor of the blood pump was simulated and the output blood pressure waveform is shown in Figure 19a. The peak blood pressure is $70 \mathrm{mmHg}$, which is lower than the normal human blood pressure. At this time, the impeller speed was set at different values to study the change law of the axial suspension position when the impeller speed changed under specific disturbance. It can be seen from Figure 19b that the impeller has achieved a stable suspension under the action of external disturbance. Under the same external disturbance, the axial displacement of the impeller changes greatly compared to that without the external disturbance, indicating that the external fluid impact can lead to the displacement of the impeller suspension position, and the impeller could move axially with a certain frequency with the action of the external disturbance. In addition, the change of impeller speed could also affect the impeller suspension position. Thus, it was found that an increase in the speed led to a higher suspension clearance and a better suspension stability.

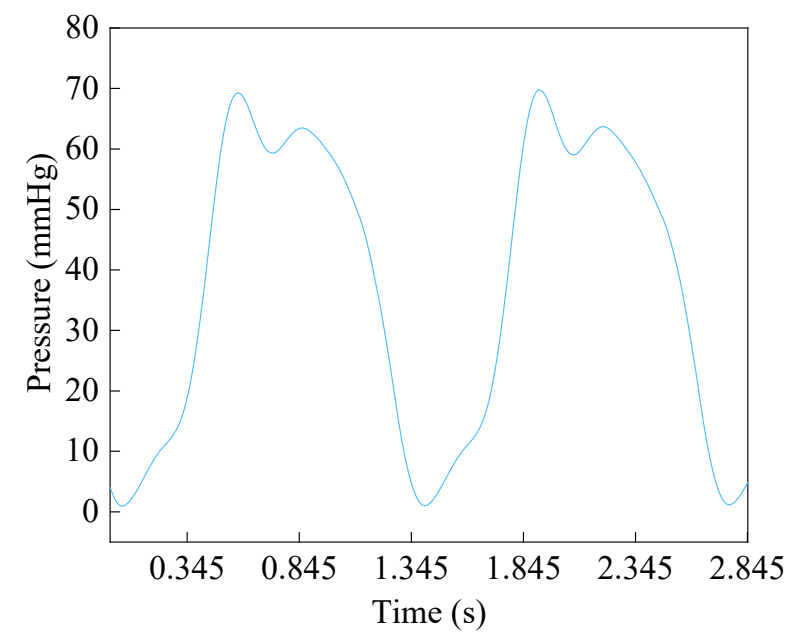

(a)

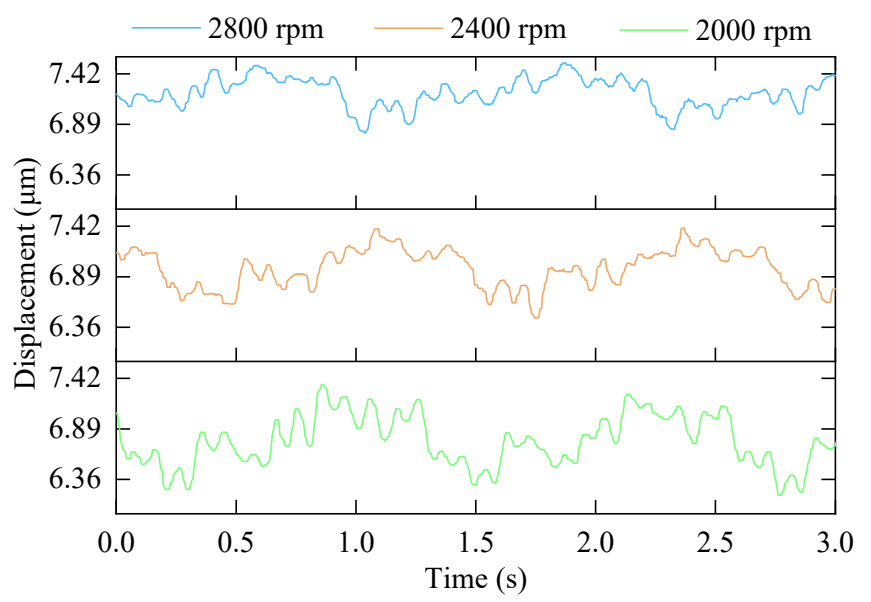

(b)

Figure 19. Pressure corresponding to external fluid disturbance at constant speeds: (a) Pressure waveform; (b) Axial displacement.

Figure 20a shows the disturbance waveform applied to the blood pump by the extracorporeal mock circulatory loop. The pulsation frequency of Case 1 to Case 4 continues to decrease, but the pulsation amplitude of the blood pressure shows a persistent increase. When the blood pump impeller was run at a constant speed of $2600 \mathrm{rpm}$, the extracorporeal mock circulatory loop gave an output for the four blood pressure waveforms shown above to simulate the suspension stability of the blood pump under the action of different frequencies and the blood pressure waveforms pumped by the failed heart. Under the external fluid disturbance, the blood pump impeller floated up and down in the axial direction, and its frequency was consistent with the external disturbance frequency. The greater the external fluid pressure, the greater the inlet pressure of the hydrodynamic bearing, and the more obvious the dynamic pressure effect. It was found that a larger the hydrodynamic force increased the suspension clearance of the blood pump. The results are shown in Figure 20b. The results show that the fluid pressure significantly affected the axial suspension position of the impeller. Compared to the axial clearance, the axial displacement is small. Before the blood pump starts, the magnetic suspension system is unstable, and the impeller is generally adsorbed on the inlet side casing. When the rotating speed of the blood pump increases, the dynamic pressure effect increases, the hydrodynamic force counteracts the attraction of the permanent magnet bearing and is in the force balance under the action of the inlet fluid, so that the impeller is separated from the contact with the pump casing and is in a suspended state. Additionally, the hydrodynamic force is slightly greater than that 
of the permanent magnet bearing. Therefore, the axial displacement is small relative to the gap.

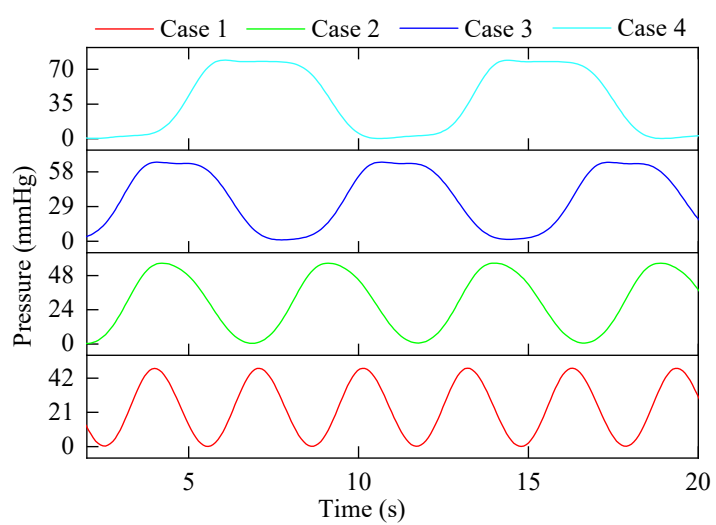

(a)

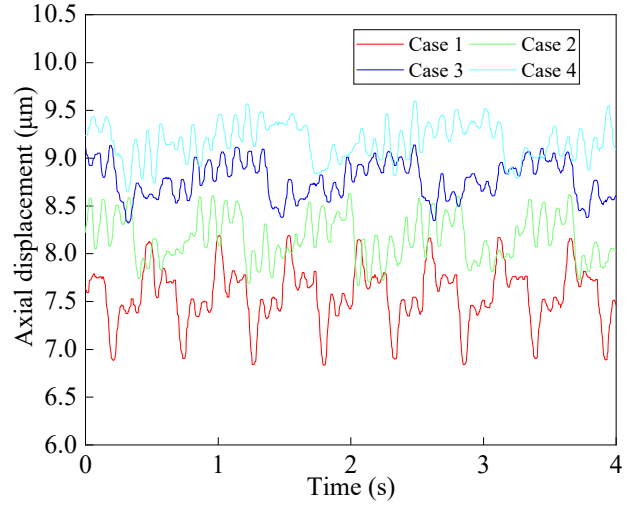

(b)

Figure 20. Effects of different external disturbances on suspension performance of the rotor at constant speeds: (a) Pressure waveform; (b) Axial displacement.

\section{Conclusions}

The blood pump with a suspension system eliminates the problems of wear, heat, and hemolysis caused by the mechanical bearings and greatly improves the blood compatibility. However, the realization of a stable suspension of the rotor plays a vital role in improving the durability and blood compatibility of the blood pump. In the present study, the magnetic suspension system composed of a blood pump with single-winding bearingless motor and permanent magnet bearing was designed, the axial dynamic model of bearingless motor rotor was established, and the accuracy of the electromagnetic force and the torque theoretical model was verified using a simulation. The radial suspension stability of the rotor was analyzed, the axial dynamics model of the rotor with a magnetic-hydrodynamic double suspension system was established, the suspension stability was analyzed from the perspective of stiffness, and a hydrodynamic bearing was designed to eliminate the influence of axial negative stiffness on the suspension stability. By solving the Reynolds equation, the influence law of the spiral groove structural parameters on stiffness and hydrodynamic force was studied. When the number of grooves was 20, the spiral angle was $45^{\circ}$, the groove width ratio was 0.5 , and the groove depth was $0.1 \mathrm{~mm}$, the system exhibited an optimal axial support performance. Finally, the suspension stability under the fluid impact was studied by building an extracorporeal mock circulatory loop. The experimental results showed that the bearingless rotor could float stably and ensured the suspension stability under the impact of external fluid, which laid a foundation for the follow-up active suspension control and practical clinical application. In addition, the structural parameters and axial clearance control of the hydrodynamic bearing affected the blood compatibility of blood pump. Therefore, the structure of magnetic suspension system and hydrodynamic bearing needs to be optimized by integrating the suspension performance and blood compatibility.

Author Contributions: Y.W. and P.S. conceptualized the study; P.F. and L.Z. performed the formal analysis; P.S. worked on the methodology and software-related evaluations; L.L. and Y.C. wrote, reviewed and edited the manuscript. All authors have read and agreed to the published version of the manuscript.

Funding: This study was funded by the National Natural Science Foundation of China (grant number 51875143).

Institutional Review Board Statement: Not applicable.

Informed Consent Statement: Not applicable. 


\section{Data Availability Statement: Not applicable.}

Conflicts of Interest: The authors declare no conflict of interest.

\section{References}

1. Han, J.; Trumble, D.R. Cardiac Assist Devices: Early Concepts, Current Technologies, and Future Innovations. Bioengineering 2019, 6, 18. [CrossRef] [PubMed]

2. Simon, M.A.; Bachman, T.N.; Watson, J.; Baldwin, J.T.; Wagner, W.R.; Borovetz, H.S. Current and Future Considerations in the Use of Mechanical Circulatory Support Devices: An Update, 2008-2018. In Annual Review of Biomedical Engineering; Yamush, M.L., Ed.; Annual Reviews: San Mateo, CA, USA, 2019; Volume 21, pp. 33-60.

3. Ward, R.A.; Wellhausen, S.R.; Dobbins, J.J.; Johnson, G.S.; Devries, W.C. Thromboembolic and Infectious Complications of Total Artificial Heart Implantation. Ann. N. Y. Acad. 2010, 516, 638-650. [CrossRef] [PubMed]

4. Sheikh, F.H.; Russell, S.D. HeartMate II continuous-flow left ventricular assist system. Expert Rev. Med. Devices 2011, 8, 11-21. [CrossRef] [PubMed]

5. Kounis, N.G.; Soufras, G.D.; Davlouros, P.; Tsigkas, G.; Hahalis, G. Thrombus Formation Patterns in HeartMate II ContinuousFlow Left Ventricular Assist Devices: A Multifactorial Phenomenon Involving Kounis Syndrome? Asaio J. 2014, 60, 369-371. [CrossRef] [PubMed]

6. $\quad$ Bourque, K.; Gernes, D.B.; Loree, H.M.; Richardson, J.S.; Poirier, V.L.; Barletta, N.; Fleischli, A.; Foiera, G.; Gempp, T.M.; Schoeb, R. HeartMate III: Pump design for a centrifugal LVAD with a magnetically levitated rotor. Am. Soc. Artif. Intern. Organs J. 2001, 47, 401-405. [CrossRef] [PubMed]

7. Hoshi, H.; Katakoa, K.; Ohuchi, K.; Asama, J.; Shinshi, T.; Shimokohbe, A.; Takatani, S. Magnetically suspended centrifugal blood pump with a radial magnetic driver. ASAIO J. 2005, 51, 60-64. [CrossRef] [PubMed]

8. Hoshi, H.; Shinshi, T.; Takatani, S. Third-generation blood pumps with mechanical noncontact magnetic bearings. Artif. Organs 2010, 30, 324-338. [CrossRef] [PubMed]

9. Masuzawa, T. Magnetically suspended motor system applied to artificial hearts and blood pumps. Proc. Inst. Mech. Eng. Part I J. Syst. Control. Eng. 2017, 231, 330-338. [CrossRef]

10. Chen, Z.F.; Li, Z.X.; Ma, H.Z. Design and performance characterization of a novel salient-pole surface-mounted permanent magnet synchronous machine. Int. J. Appl. Electromagn. Mech. 2018, 56, 347-355. [CrossRef]

11. Chou, P.; Yang, S.; Jhong, C.; Huang, J.; Chen, J. High-Precision Permaent Magent Motor Design for Satellite Attitude Control with High Torque Density and Low Torque Ripple. In Proceedings of the IECON 2019-45th Annual Conference of the IEEE Industrial Electronics Society, Lisbon, Portugal, 14-17 October 2019; pp. 802-805.

12. Nasiri-Zarandi, R.; Ghaheri, A.; Abbaszadeh, K. Cogging Torque Reduction in U-Core TFPM Generator Using Different HalbachArray Structures. In Proceedings of the International Symposium on Power Electronics, Electrical Drives, Automation and Motion (SPEEDAM), Amalfi, Italy, 20-22 June 2018; pp. 1153-1158.

13. Fu, Y.; Hu, Y.; Huang, F.; Zhou, M. The Impact of Pulsatile Flow on Suspension Force for Hydrodynamically Levitated Blood Pump. J. Healthc. Eng. 2019, 2019, 8065920. [CrossRef] [PubMed]

14. Kosaka, R.; Yoshida, F.; Nishida, M.; Maruyama, O.; Yamane, T. Bearing gap adjustment for improvement of levitation performance in a hydrodynamically levitated centrifugal blood pump. In Proceedings of the Engineering in Medicine \& Biology Society, Milan, Italy, 25-29 August 2015.

15. Wang, L.; Tang, X.; Yun, Z.; Xiang, C.; Lu, Z. Analysis of a Novel Magnetic-Hydrodynamic Double Levitated Motor for an Implantable Axial Flow Blood Pump. Shock. Vib. 2020, 2020, 8833994. [CrossRef]

16. Chung, M.; Nong, Z.; Tansley, G.D.; Yi, Q. Experimental Determination of Dynamic Characteristics of the VentrAssist Implantable Rotary Blood Pump. Artif. Organs 2015, 28, 1089-1094. [CrossRef] [PubMed]

17. Kosaka, R.; Yasui, K.; Nishida, M.; Kawaguchi, Y.; Maruyama, O.; Yamane, T. Optimal bearing gap of a multiarc radial bearing in a hydrodynamically levitated centrifugal blood pump for the reduction of hemolysis. Artif. Organs 2014, 38, 818-822. [CrossRef] [PubMed]

18. Yasui, K.; Kosaka, R.; Nishida, M.; Maruyama, O.; Kawaguchi, Y.; Yamane, T. Optimal design of the hydrodynamic multi-arc bearing in a centrifugal blood pump for the improvement of bearing stiffness and hemolysis level. Artif. Organs 2013, 37, 768-777. [CrossRef] [PubMed]

19. Kataoka, H.; Kimura, Y.; Fujita, H.; Takatani, S. Measurement of the Rotor Motion and Corresponding Hemolysis of a Centrifugal Blood Pump With a Magnetic and Hydrodynamic Hybrid Bearing. Artif. Organs 2015, 29, 547-556. [CrossRef] [PubMed]

20. Nguyen, Q.D.; Ueno, S. Analysis and Control of Nonsalient Permanent Magnet Axial Gap Self-Bearing Motor. IEEE Trans. Ind. Electron. 2011, 58, 2644-2652. [CrossRef]

21. Asama, J.; Hamasaki, Y.; Oiwa, T.; Chiba, A. Proposal and Analysis of a Novel Single-Drive Bearingless Motor. IEEE Trans. Ind. Electron. 2013, 60, 129-138. [CrossRef]

22. Cheng, S.; Olles, M.W.; Burger, A.F.; Day, S.W. Optimization of a Hybrid Magnetic Bearing for a Magnetically Levitated Blood Pump via 3-D FEA. Mechatronics 2011, 21, 1163-1169. [CrossRef] [PubMed]

23. Pohlmann, A.; Hameyer, K. A study on permanent magnet topologies for hybrid bearings for medical drives applied in Ventricular Assist Devices. Arch. Electr. Eng. 2011, 60, 371-380. [CrossRef] 